\title{
1. Conflicts of interest, and guiding principles for their resolution within IP's constitutional framework
}

\section{THE POSITIVE NORMATIVE SCENARIO}

\section{The Two Key Constitutional Freedoms Overarching Modern IP Law}

Modern intellectual property law's basic tenets reflect the institutional framework created by the 'dual revolution' (E. Hobsbawm), economic and political, that in Europe, as in the US, fostered the Age of Enlightenment. ${ }^{1}$ This framework is rooted in two fundamental freedoms of constitutional rank, recognized under the aegis of the principle of the legal equality of citizens.

The first freedom is that of economic enterprise, and consequently of competition, ${ }^{2}$ i.e. the right of each individual to access the market and to operate there under conditions of equal treatment. The traditional rationale is that such freedom(s) prize the capacity to innovate and create as well as widen the choices of consumers, thus also (indirectly) promoting their welfare.

1 On the relationship between the industrial revolution(s) and the new political-institutional structure inspired by the ideals of the Enlightenment, I suggest starting with E. Hobsbawm, in particular, The Age of Revolution: Europe: 1789-1848, Weidenfeld and Nicolson, 1962 and Industry and Empire: An Economic History of Britain since 1750, Weidenfeld and Nicolson, 1968; see also P. M. Deane, The First Industrial Revolution, Cambridge University Press, 1967. Italian reading researchers might also conveniently consult (also for its exhaustive references therein) L. Geymonat, Storia del pensiero filosofico $e$ scientifico, Vol. III, Capitolo primo - Il secolo dei Lumi, Milan (Garzanti), 1971.

2 Freedom of competition is 'the pluralistic refraction of freedom of enterprise' (G. Minervini, Concorrenza e consorzi, in Trattato dir. civ., F. Grosso and F. Santoro Passarelli (eds), Milan, 1965, p. 7), an individual right of constitutional rank (see also Charter of Fundamental Rights of the European Union (2000/C 364/01), article 16). 
The second freedom is the fundamental freedom of expression in the broadest sense, i.e. of 'producing' and disseminating as well as 'receiving' information, opinions and the fruits of thought and artistic and scientific endeavour. In sum, spreading and accessing knowledge in manners and terms hopefully capable of equitably balancing the interests of 'creators' with those of 'users'.

This new philosophical, political and institutional framework radically altered the policies, and ensuing legal rules, on industrial and commercial activities as well as on the production and spreading of technology and culture (arts and sciences). The policies and rules in the previous age of the guilds through to the mercantile system were basically grounded on corporative and/or individual privileges, ${ }^{3}$ i.e. in essence, on limitations of access to the production of and markets for goods. This framework was emblematic of a command economy seeking to control not only economic relationships but also the spreading of ideas and information (whose circulation was subject, as known, to an essentially censorshiptype regime; see also Chapter 3 ).

In contrast, in the new institutional context, the granting of exclusive industrial and intellectual property rights historically emerged as a reflection of the general interest in the development of the "market economy', i.e. pluralistic (competitive) entrepreneurial initiative, and the enrichment of technical, scientific and cultural knowledge. ${ }^{4}$ In that framework intellectual property rights were structurally and functionally rooted in a dialectic relationship between 'exclusion' and 'access' (more below, §9), and represented, as has been well said, islands in a sea of liberty. In other words, the granting to private parties of rights to exclude unauthorized third parties from access to the protected immaterial goods (in a manner and extent that varies according to each IPR) is of an exceptional nature, hence is acknowledged on a numerus clausus basis. IPRs are exceptions to those fundamental freedoms.

Moreover, these exceptional rights are ultimately warranted on the basis of general interest-related functional/instrumental considerations. In particular, as concerns patents and copyrights, they were granted as

3 As in Venetian patents of the mid-15th century, individual privileges often contrasted (and were sometimes granted for that very purpose) with the monopolies enjoyed by corporations, thereby also paving the way for the subsequent citizen's equality under the law sanctioned by the industrial revolution(s)' constitutional framework.

4 In the recalled famous words of the US Constitution, the granting of 'limited rights' to authors and inventors is conceived to 'promote the progress of science and the useful arts' (article I, section 8, clause 8). 
means to the end of satisfying the general interest to the promotion of 'the progress of science and the useful arts' (as article I, section 8, clause 8 , of the US Constitution recites). As concerns trademarks and other distinctive signs, the rights thereon were granted to enhance the transparency of modern, typically competitive, markets.

This institutional, functionally oriented framework offers the best clue to approaching the study of modern principles of IP law, at both national and international level (here, in particular, with reference to the TRIPs Agreement (below) and the so-called acquis communautaire). Moreover, while basically rooted in the two constitutional freedoms of enterprise/ competition and expression, this framework is being growingly enriched thanks to an emerging academic and jurisprudential line of thought, by further values/objectives of (formal or substantive) constitutional rank, such as the protection of health, environment, privacy, and human rights at large. ${ }^{5}$

\section{From Classic Duality ('Industrial' and 'Intellectual') to the Progressive Articulation and Hybridization of the Fundamental Paradigms}

In examining how modern IP law has come about, of key importance is the diversification of the fundamental paradigms of industrial and intellectual property: patent, trademark, and copyright. This diversification is historically rooted in a series of regulations introduced to specifically protect the new results of creative activity and the firms' distinctive signs - trademarks first and foremost.

As regards the former, it should be noted that all normative models embraced by the modern IP legal regimes (whose precursors were, as well known, the Venetian patents, then the statutes of King James I and Queen Anne $)^{6}$ highlighted a fundamental dualism rooted in the different nature and function of the new result protected. On the one hand, innovations of practical fruition are protected in relation to the conceptual content; on the other hand, new works of merely intellectual fruition (the adverb of course signalling the difference in the subject matter, certainly not in the value) are protected in relation to their expressive character (more below, Chapter 3 ).

This distinction (which the classic nomenclature reflected by distinguishing industrial from intellectual property) was consecrated towards

5 On this new frontier of academic thought, more below, $\S 11$.

6 Statute of Monopolies of James I, 1624, on industrial monopolies; Statute of Anne, 1710, on copyright. 
the end of the 19th century in the great Universal Conventions of Paris and Berne. In the wake of the widespread expansion in production and trade produced by the first and already incipient second industrial revolution (from steam power to electro-mechanics to early telecommunication systems), those Conventions sought to give a rational and essentially homogeneous structure ${ }^{7}$ to transnational business relations hinging on the exploitation of intangible assets that had become strategic levers of competition and hence a new source of the wealth of nations.

Thus, on the one hand (Paris Union Convention [PUC] for the Protection of Industrial Property, 1883), reference was made to the general paradigm of patent for industrial invention and utility model for the promotion and spread of innovation through rules designed to protect the conceptual substance of creations of practical fruition, i.e. technology. That paradigm was then 'reshaped', as concerns Europe, by the European Patent Convention (EPC), signed in Munich in 1973 (to which the 1975 Luxembourg Convention on the European Patent for the Common Market aimed to give 'unitary effect' for the Common Market) ${ }^{8}$ and subsequently revised in 2000 (EPC 2000: now simply 'EPC'). ${ }^{9}$

On the other hand (Berne Convention for the Protection of Artistic and Literary Works, 1886), reference was made to a paradigm whose features were sharply different, ${ }^{10}$ i.e. copyright, aimed at the promotion and spread of creative works for intellectual fruition ('œuvres littéraires et

7 An effect of the 'assimilation' of the citizens of the various Member States: see article 2 of the Paris Union Convention (PUC) for the Protection of Industrial Property, signed 20 March 1883, last revised in Stockholm in 1967.

8 The Luxembourg Convention never entered into force, but many of its substantive provisions (e.g. the ones on patent scope) acted as blueprints for many national legislations (including Italy). The 'unitary effect' is now trying to see the light under Reg. 1257 and Reg. 1260, as of 17 December 2012 (for the substantive discipline) and the Agreement as of 19 February 2013 on the 'Unified Patent Court' (for the jurisdictional profiles). Until the Agreement enters into force (it needs to be ratified by at least 13 Member States), even the Regulations cannot be applied (articles 18.2 and 18.3 Reg. 1257/2012, and 7.2 Reg. 1260/2012). PS: What after Brexit?! (My guess is that the UK will 'remain' within the Unitary Patent System.)

9 See article 1.2 Reg. 1257 cit.

10 Just think, for example, of the different terms of the exclusive protection: much shorter and fixed for technological creations compared to artistic ones. This and other differences will be specifically discussed in Chapter 3. 
artistiques', to cite article 1 of the Berne Convention) ${ }^{11}$ through rules designed to protect the expressive aspect of the works.

As regards distinctive signs (firms' names, signboards, and above all trademarks, the fundamental paradigm), ${ }^{12}$ they too were brought within the aegis of industrial property and hence regulated by the Paris Convention along with patents. Rightly so, given that they are tools of industry and commerce typically employed within a framework of competition - tools whose essential mission is to protect (the truth of) business identity as regards not only the identification of the firm but also that of the specific products manufactured and offered for sale, ${ }^{13}$ thus ensuring the truth of information essential to guarantee the transparency of a typically competitive, i.e. 'plural' market ${ }^{14}$ in the interests of those who operate therein, whether as producers/distributors or as consumers.

The classic separation between the two great Conventions of the late 19th century was formally recomposed in the Agreement on Traderelated Aspects of Intellectual Property Rights (TRIPs), signed in Marrakech on 15 April 1994 and entered into force on 1 January 1995. As known, participation to the TRIPs Agreement is a condition of membership of the World Trade Organization. TRIPs, strongly advocated by the most industrialized nations - the USA first and foremost ${ }^{15}$ - represents the new IP 'universal convention' stipulated in the wake of the new industrial revolution marked by information and bio-technologies. TRIPs has redefined the rules on intellectual property around 'minimum' standards of protection that essentially reflect established legal models of industrially advanced countries, aimed at regulating immaterial assetsrelated international competition between advanced countries and between them and Developing and Least Developed Countries (below, $\S 14$, in this chapter).

11 See below Chapter 3 for the extension of the copyright paradigm to certain types of utilitarian products.

12 Which embraces both individual trademarks (of a firm) and the collective ones (private trademarks, not to be confused with official denominations of geographical origin) (below, Chapter 4, fns 21, 57, 58, and accompanying text).

13 The two profiles are reflected in the distinction between 'general' and 'product' trademarks. To give a clear example, Ferrero distinguishes the Italian confectionery producer from other manufacturers, as Mon Chéri does vis-à-vis other chocolate-coated cherries (see Chapter 4, § 1).

14 More below, Chapter 4.

15 Of particular interest are the comments by J. H. Reichman in the run up to TRIPs: 'The TRIPS Component of the GATT's Uruguay Round: Competitive Prospects for Intellectual Property Owners in an Integrated World Market', Fordham L. J., 1999, 181, 216. 
As said, the Agreement formally brings together in one single convention, under a common core of 'fundamental principles' (articles 1-8) the classical regulatory dichotomy between industrial and intellectual property, aiming to express on a global scale a basically unitary regulatory framework of international trade relations linked to the exploitation of intangible goods as a source of competitive advantage.

However, in modern times, well before the advent of the TRIPs Agreement, this classic dualism had gradually lost importance and systemic meaning due to the establishment of various centrifugal tendencies. On the one hand there has been a trend towards regulatory fragmentation within the context of the single paradigms: think of the variety of special patent models (for plant varieties, biotechnologies and semiconductor topography) $)^{16}$ and the array of (systems of) rights connected to copyright. On the other hand, there has been a growth in hybrid and cumulative paradigms that have become a feature of some special regulations regarding certain industrial sectors. For example, protection of industrial design is achieved through a system of registration that blends elements of patent law and features of the protection of distinctive signs - and may also overlap with the protection granted by copyright and shape trademarks' registration.

A further factor contributing to the complexity of the regulatory framework is the way that certain rules, normally designed to further competition, 'interfere' with the regime of IP paradigms. I am referring, firstly, to antitrust law (at the European level: articles 101-108 TFEU, related Directives and Regulations, established EU Courts' and Commission's decisions jurisprudence [altogether, acquis communautaire]), whose mission is precisely to intervene to keep open market arteries at risk of obstruction by practices and operations - including those based on the exploitation of IPRs - which threaten the survival of effective ('workable') competition.

The overall framework must also include the rules on unfair competition (articles 10-bis and 10-ter of the Paris Union Convention, expressly referred to by article 39 TRIPs), which prohibit certain misbehaviours to the prejudice of individual competitors (not 'the market' as such). Misbehaviours which can 'touch' (interfere, overlap) the exercise of IPRs - think for example of the passing off of patented products' distinctive features, or misleading advertising focused on trademarks).

16 'Stellar' is how the modern patent system is defined by V. Di Cataldo, in A. Vanzetti and V. Di Cataldo, Manuale di diritto industriale, Milano, 2012, 382. 
The complex intersection(s) between IP law and competition law(s) will be extensively dealt with in Chapter 5 . Here, I just wish to emphasize that, in regard to antitrust, its 'corrective' role vis-à-vis anti-competitive ways of exercising, and even acquiring, IP entitlements, ${ }^{17}$ should in principle be activated, first of all, in default of a remedial interpretation of IP's own rules, capable of activating the pro-competitive 'antibodies' often built into said rules (in different ways and degrees in respect of each IPR). 'Cleaning the house' by internal means - for example, getting a patent declared null and void, with erga omnes efficacy - would remove once and for all 'unworthy' exclusive rights - undeserving legal barriers obnoxious to freedom of competition. Conversely, an antitrust scrutiny would not only intervene after the IPR has been 'abusively' exercised, requiring the additional (often complex and costly) assessment of a dominant position and a risk of market foreclosure, but - unlike an action for nullity - it would also chastise the illegitimate entitlement only in relation to those specific market circumstances of that case, rather than removing it definitely, thus leaving the 'weapon' in the hands of maverick holders, available for future ambushes to competitors.

On a different level, antitrust can 'march in', interfering with the exercise of IPR when, in Hanns Ullrich's words, 'legislators ... fail to properly define the limits of exclusive property rights' - this, in particular, 'in new situations, especially with regard to new technologies'. ${ }^{18} \mathrm{On}$ this distinct profile, see below Chapter 5.

\section{3 'Separatist' Constructions of the Latter: A Critique}

All of the mentioned factors, commencing from the intrinsic deep differences in the main features (object, function, scope, duration, limitations of protection, modes of intersection with competition law, etc.) of the single fundamental IPRs, have encouraged the rise and diffusion of a 'separatist' approach to research and teaching: one that seeks to construe the IP legal paradigms as 'microsystems' in isolation one from the other - and often also from the overall complex regulatory

17 The traditional distinction between the exercise of IPRs - subject to antitrust scrutiny - and entitlement thereof (as such 'off limits') has been progressively blurred (see S. D. Anderman, EC Competition Law and Intellectual Property Rights: The Regulation of Innovation, Oxford University Press, 2000, $12 \mathrm{ff}$.), up to the recent dismissal by EU - e.g. Astrazeneca - and national jurisprudence - e.g. Pfizer, Italian case. More below, Chapter 5, section I.

18 H. Ullrich, 'Expansionist Intellectual Property Protection and Reductionist Competition Rules: A TRIPS Perspective', J. Int'l. Econ. Law, 2004, 401. 
framework concerning the activities and interests involved in the exercise of intellectual property rights.

That separatist approach has undoubtedly contributed to producing in-depth - highly in-depth - analytical results. But if taken to an extreme it exposes the interpreter to the risk of appearing the obedient servant of a method of rule-making influenced by sectoral interests and often insensitive to systemic consistency. This sacrifices two basic methodological requirements: firstly, avoiding internal contradictions within IP law, i.e. interpreting the rules on a specific paradigm in a manner that will not bypass the rules that on the same subject matter another paradigm expresses in relation to a distinct (as such intrinsically noncontradictory) protective function. Secondly, as hinted, a 'sealed compartments' approach also risks marginalizing the role of normative principles of constitutional rank (in the formal and/or substantive sense) concerning economic activities involving IPRs. These principles, far from constituting vague wishful directives to the legislator, do play a primary role $^{19}$ (also) in guiding the interpretation of the ordinary IP law rules. Their importance is paramount: they express the ethical-political canons of the organized community, historically formulated and established through often heated debates among the bearers of various social interests (and ensuing ideological views). Neglecting those principles or not effectively valuing them as the key to (also) reconstructing IP law rules leads to the further and even more serious risk of not understanding where a certain line of interpretation leads to (and why) or - put another way, 'who gains and who loses' - following the adoption of one interpretation rather than another. The risk is that jurists would be reduced to skilled exegetes and/or erudite specialists ('techies', as Eleanor Fox colloquially labels them) - well able to see the trees but not the forest or the wind that blows through it - or, more dangerously, advocates brilliant in using exegetics and specialist knowledge to technically mask solutions informed by (often undeclared) particular interests and objectives.

\section{IPRs’ ESSENTIAL SCOPE}

\section{What IPRs do not Per Se Guarantee}

What is the essential core of IPRs according to positive law? What is the permanent nucleus of holders' rights even vis-à-vis the conflicts that the

19 Below, in this chapter, section VI. 
exercise of intellectual property rights triggers, as we shall discuss in a while, with other individual and/or collective interests that claim access to intangibles?

As a 'follower' of Humpy Dumpty, ${ }^{20}$ let me clarify - that by 'essential core' I refer both to the power to exclude free riders and the symmetrical power (below, in this $\S$ and the next one) to include selected third parties in the exploitation of the protected intangible asset. Such dual empowerment is granted to IPR holders per se, i.e. as an immanent effect of the entitlement, associated (as concerns the faculty to include) with the individual freedom of contract, hence the right of disposition (Verfügungsrecht) of said rights. Needless to say, this empowerment does not per se encompass, or legitimate, possible 'further' uses of an IPR that might determine or facilitate the achievement of unlawful effects - anticompetitive in particular.

The foregoing assumptions are supported by highlighting what IPRs do not guarantee.

They do not guarantee the right to produce and distribute. The green light to manufacturing and marketing a drug is not given by the granting of the patent but by clearance from the Public Health authorities. The distribution of a literary work that enjoys copyright protection may be blocked if it incites racial hatred, analogous to the sale of dangerous goods branded by a valid trademark.

They do not guarantee - contrary to what one often reads - the imposition of differential prices - hence, possibly 'monopolistic' profits. If an invention or a new musical work meets no or poor success, a patent or copyright will not be able to keep prices above the average market level. The analogous applies to a trademark that distinguishes a failed product. In any event, if the protected goods circulate, as is normally the case, in a legal and economic situation of effective competition between substitutes the holder will have no choice but to adjust the price to the level determined by that very competition.

They do not per se guarantee a dominant position or - in US terms market power such as to significantly foreclose competition. The achievement of such position depends - again - on the degree of effective 'competition by substitutes'. Thus, for example, dominance may be (presumedly) achieved thanks to an IPR protecting an intangible 'indispensable' for achieving a certain functional objective ('essential facility'), even sub specie of a technology formally selected (or however

20 L. Carroll, Through the Looking Glass, 1871, Chapter 6. 
assessed) as 'standard' or 'essential' component of a 'standard' (below, Chapter 5).

\section{The Power to Exclude ...}

All this confirms that the 'core' exclusive protection afforded by IPRs per se consists in nothing more than the power to forbid straight/die hard, economically (competitively) significant free riders to access the protected intangibles. In this sense and only in this sense can one say that intellectual property rights provide an incentive to invest and operate. ${ }^{21}$

As a general corollary, any form of exercise of the exclusionary power of the holders that stretches beyond the exclusion of economically significant free riders or the autonomously agreed or imposed inclusion of third parties as licensees, ${ }^{22}$ finds the IPR holder acting at its own risk. This is particularly so when IPRs are exercised in contrast with competition law rules (think, for example, of the imposition of discriminatory terms in granting patent licences) or with copyright norms and principles safeguarding the right to freely access culture and information (think, for example, of the abusive encryption of materials subject to legitimate free access: see Chapter 3, §17 (D)).

It must be made clear that even when they are merely exercised to exclude free riders, IPRs do not relate to any unauthorized use. They relate solely to those unauthorized uses that can be termed as 'economically significant' for the holders, ${ }^{23}$ in that they entail a risk for the latter of suffering losses likely to thwart the expectation of recovering their investments and earning 'appropriate' remuneration ${ }^{24}$ for the activities that originated the new invention or intellectual work. As already hinted, it is that type of free riding - of an essentially competitive character - to which the classic rationale (Bentham, below, fn 35) for granting intellectual property rights refers.

21 It is however a partial incentive (in that all the other economic risks remain uncovered), but not for that reason less relevant, as the case may be: especially in relation to capital-intensive activities and long-term investments.

22 See below $\S 6$.

23 See D. Lim, Patent Misuse and Antitrust Law, Edward Elgar, 2013, p. 3, fn 1. More in Chapter 5.

24 'Appropriate, not maximized': here, in coherence with the principle of 'proportionality' (below, § 22), I assume the indication of the CJEU in Premier League, C-403/08, as of general reach throughout the field of IP law. 
In this perspective, let us consider the various 'exceptions' 25 that limit the scope of the exclusive protection: (a) as regards patents, the merely private or merely experimental uses, or (even commercial but 'noncompetitive') extemporaneous individual preparations made by a pharmacist (below, §21); (b) as regards copyright, certain 'free uses' of 'informatory purpose' allowed by Berne Convention (article 2-bis) and the 2001 InfoSoc Directive (below, Chapter 3); (c) as regards trademarks, the freedom to use them in a merely descriptive function - for example, to impart information about the destination of spare parts (article 12c) (Reg 207/09)). On the issue of 'exceptions' to IPR holders' exclusive power, more below, when analysing the single paradigms (Chapters 2, 3, and 4).

\section{6 ... and to 'Include'}

As hinted, this conclusion is far from exhaustive. The right to exclude unauthorized third parties goes hand in hand with the freedom to choose which third parties to include/associate (as co-venturers, licensees, distributors, etc. $)^{26}$ in the exploitation of the protected intangible assets. This typically occurs in order to realize the plans for research, production and distribution that the holder by itself could not achieve or could do only in a costlier manner. Such right to include - itself an expression of the right to dispose of one's own right, in turn a corollary to the general principle of freedom of contract - is more and more frequently exercised

25 I write 'exceptions' in inverted commas, since they relate to exercises of freedoms of constitutional rank vis-à-vis their public interest rationale - research, teaching, public information, market transparency. They are in truth 'exceptions' to the 'main' exceptions - systemically, IPRs are 'exceptions'! (above, § 1). Hence, as a corollary, the aforesaid 'exceptions' should not be subject to 'strict interpretation'. See M. Mimler, '3-D Printing, the Internet and Patent Law - A History Repeating?', Riv. Dir. Ind., I, 2013, 352. More below, Chapters 2, 3, and 4.

26 See S. Dusollier, 'Inclusivity in Intellectual Property', in G. Dinwoodie (ed.), Intellectual Property and General Legal Principles: Is IP a Lex Specialis?, ATRIP Intellectual Property Series, Edward Elgar, 2015, p. 91 et seq.; D. R. Gnyawali and B. J. R. Park, 'Co-opetition Between Giants: Collaboration with Competitors for Technological Innovation', Research Policy, 2011, 650 et seq.; K. M. Saunders, 'The Role of Intellectual Property Rights in Negotiating and Planning a Research Joint Venture', Marquette Intellectual Property Law Review, 2003, 75. Of course, this inclusive profile is quite distinct to that founded on provisions of compulsory licences, either established 'within' the patent regime (as e.g. in article 31.1 TRIPs: below, Chapter 2) or stemming from (intrinsically regulatory) 'antitrust interference' on IPRs' exercise (below, Chapter 5, section I). 
by entrepreneurs, even competing ones - 'coopetitors' 27 - who acknowledge a reciprocal interest in sharing/exchanging valued technological assets. $^{28}$

It is worth emphasizing that this inclusive profile of IPRs - the other side of the coin, so to speak (or the other face of Janus) takes on an ever-growing, nay, primary role from an economic standpoint, so as to suggest keeping a safe distance from exhausting the vision of the essential function of IPRs in the exclusionary power tout court. Indeed, while this latter is exercised in relation to disputes concerning the validity or infringements of IPRs, i.e. in occasional circumstances, the normal, 'day-to-day entrepreneurial exploitation of the intangible assets occurs more and more typically through inclusion of those third parties with whom the IPR holder chooses to cooperate as concerns research/ production/distribution.

\section{FIRMS AS 'FINAL HOLDERS' OF (ECONOMIC) INTELLECTUAL PROPERTY RIGHTS}

\section{The Typical Necessity of Individual Creators of IPR Protectable Intangibles to Alienate their Creation to Firms for Commercial Exploitation}

As a rule (i.e. except for the specific cases where the law directly grants to firms the entitlement of IPRs on the works realized by their employees), ${ }^{29}$ intellectual property rights are originally attributed to individuals:

27 Cooperation among competing undertakings is subject to limits that European antitrust law lays down (with an increasingly benign eye): ex multis, G. Ghidini and A. Stazi, 'Coopetition: The Role of IPRs', in D. Beldiman (ed.), Innovation, Competition and Collaboration, Edward Elgar, 2015, p. 15.

28 This type of entrepreneurial strategy has particularly emerged where the protected technology has been assessed as an industrial standard, or essential part of a standard (as in the case of Standard Essential Patents [SEPs]), 'patents that are essential to the standard (in that they must be practiced to accomplish the standard)': Judge J. Robart, Order No. C101823JLR in Microsoft v. Motorola, 24 September 2013, p. 3). In short, patented technologies that currently have no alternatives (substitutes) to accomplish specific function or to do so efficiently. Below, Chapters 2 and 5.

29 Whereas employees' inventions are regulated by national laws (hence sometimes with deep differences of regime: see also below fns 42, 43 and 44 and accompanying text), the rights on software developed by employees accrue - in default of diverse agreement - to the employer (see article 2.3 of Directive 
in other words, they are initially vested in the person of the inventor, author or trademark registrant. ${ }^{30}$ This situation is coherent with the idea (also reflected in article 27.2 of the Universal Declaration of Human Rights) $)^{31}$ that IPRs express fundamentals rights as they pertain to human beings (and not also firms, according to a convincing authoritative opinion), ${ }^{32}$ so that they may enjoy, economically and morally, the fruits of their creativity - whereas, when vested in firms, said rights should systemically be ascribed to the sphere of freedom of enterprise (below, $\S 8$, in this Chapter).

This recognition is at the root of the modern philosophical theories, born of the Enlightenment, in support of IP protection ${ }^{33}$ (in particular, with a definite economic bias, Locke ${ }^{34}$ and Bentham ${ }^{35}$ ). In this perspective, it is also worth mentioning the emphatic definition of IP as 'the most sacred of properties' ('la propriété la plus sacrée'), given (with a bit

24/09/CE). The same happens for industrial design (article 14.3 Reg 6/02/CE). In other words, as these technologies turned to copyright protection, the labourers' own rights are at risk of disappearing like the Cheshire cat (not even the grin - in form of 'moral rights' - would remain?).

30 Collective trademarks' ownership is directly attributed to associations or consortia: below Chapter 4 .

31 See also article 17.2 of the Charter of Fundamental Rights of the European Union (2000/C 364/01).

32 On this point see P. K. Yu, 'Challenge to the Development of a Human Rights Framework for Intellectual Property', in P. L. C. Torremans (ed.), Intellectual Property and Human Rights: Enhanced Edition of Copyright and Human Rights, Kluwer Law, 2008, p. 77.

33 See extensively the seminal essay by P. Drahos, A Philosophy of Intellectual Property, Dartmouth, 1996, then published by Routledge in 2016.

34 J. Locke's thinking on IP as personal property relating to the fruits of one's own labour - frequently referred to his Two Treatises of Government - is more pointedly expressed in his strong defence of copyright against the monopoly of the printers in the 1693 Memorandum against the Licensing Act, then in force in England. On this point see L. Moscati, "Un "memorandum" di John Locke tra censorship e copyright', Rassegna Forense, 2005, 603.

35 See Benthamiana: or, select extracts from the works of Jeremy Bentham: With an outline of his opinions on the principal subjects discussed in his works, edited by J. Hill Burton, Philadelphia, 1844, p. 192. In the words of Bentham: 'an exclusive privilege is necessary in order that what is sown may be reaped. In new inventions, protection against imitators is not less necessary than in established manufactures protection against thieves'. 
of plagiarism of Turgot ... $)^{36}$ by Le Chapelier, the father of the first post-revolutionary French copyright law (1791).

However, the fact that the attribution of IPRs originally concerned individuals upon the justifying evocation of their creative personality cannot conceal an immediately clear vérité de bon sens: one that has been amply incorporated into the law.

The inventor, the author and the creator of a trademark, as natural persons, have no way of economically exploiting their work except for alienating them to a firm (or going into business themselves, which is the same). Accordingly, even when they independently realized their creation, they 'must' transfer - assign, sell or license - the fruits of their ingenuity to the subject who has the means and organization to realize and distribute them on that mass scale that will enable the work, should it meet the public's favour, to remunerate also its creator. Thus, the entrepreneur 'necessarily' takes over, and exercises on the market, the entitlement of IPRs-related rights of economic exploitation. This 'transfer' is even ensured by law in the other (quite normal) cases in which the creation is realized by firms' employees. In both cases, then, the entrepreneur is the typical - 'typically necessary' - 'successor in title'37 of the individual creators, whose conflicts of interest with the former are either entrusted to private contract (thus, to a usually unequal bargaining power) or to laws on employees' inventions (usually in favour of the employers). ${ }^{38}$

Following any such transfer of economic rights, inventors or authors (and, even, if more problematically, trademarks' creators and registrants) $)^{39}$ still personally retain, with no time limit, just the 'moral'

36 Compare the 1791 Rapport de M. Le Chapelier to the aforesaid law, with the 1776 Turgot's Édit du roi portant suppression des jurandes et communautés de commerce, arts et metiers (1776), in 'Laissez Faire!', Textes choisis et présentés par A. Laurent, Les Belles Lettres, Paris, 1997, 67-74. As one can see, that emphatic formula, so often evoked by die-hard supporters of 'strong' exclusive IPRs, was in fact conceived in a context of functional links with the new institutional framework of freedom of competition.

37 EPC, article 60(1); Berne Convention, article 2(6).

38 References below, fns 42-44. Suffice it here to emphasize that said laws do not generally acknowledge any employees' rights to obtain a share of the profits accrued by the exploitation of their achievements.

39 More problematic but not impossible: think for example of the trademark owner who, as licensor thereof, opposes a certain use of the licensed trademark in a pornography-oriented advertising campaign. 
rights - which take different forms depending on the paradigm concerned (see below, especially Chapters 2 and 3). But, on an economic level, the fact remains that 'individual creators' typically depart the scene or at most play a minor role. The leading actor, the protagonist who exercises those rights, is the firm, the typically necessary 'derivative' holder thereof.

Symmetrically, only the industrial and/or commercial enterprise is able (except in the, so far, limited scenario of the 'user generated content': see below, Chapter 3) to quantitatively and qualitatively develop the work of inventors and authors (and individual creators of trademarks) such as to enable the fruition on a collective scale of technical-scientific advances and cultural innovation (and new distinctive signs, conveyors of information to the market): in that way also accomplishing a function of collective interest. ${ }^{40}$

As mentioned above, the centrality of the firm's role as the necessary holder of the rights to economically exploit IP is confirmed by multiple indications, from both international and national sources of positive law. To cite some examples:

\section{(1) Regarding patents:}

- the working requirement (provided for in many national laws ${ }^{41}$ on the basis of article 5.A of the Paris Convention and also foreseen by article 31.1 (f) of the TRIPs Agreement), that is, the duty to proceed with the industrial or commercial implementation of inventions and utility models, otherwise being subject to the imposition of compulsory licensing, or even the revocation of patent rights;

- the accrual to the firm of the right to the economic exploitation of employees' inventions, under terms and the condition that EPC, article 60(1) expressly entrusts to national systems to determine (and these in different ways do: compare, for instance, the Italian

40 See further below, $\S 8$, in this Chapter. As concerns the strictly artistic field the concrete possibility for an author to directly exploit the work on his own is basically conceivable for works not requiring a complex set-up. And especially as concerns these, the direct online diffusion of audio-visual works, the phenomenon of user generated content, is rapidly expanding. In the opposite case, it is still the 'cultural industry', the inescapable assignee - and manager - of the rights originally vested in the author. On this, more below, Chapter 3.

41 In Italy, under article 70 of the Intellectual Property Code (for models, article 86.2). 
Intellectual Property Code, ${ }^{42}$ the German Gesetz über Arbeitnehmererfindungen, ${ }^{43}$ and the UK Patents Act ${ }^{44}$ );

- the just recalled 'exceptions' to the prohibition of unauthorized exploitation based on non-entrepreneurial (ultimately, noncompetitive) uses of the patented invention, such as for private and/or research purposes (below, Chapter 2, § 12).

\section{(2) Regarding copyright:}

- the recognition of the role of the firm that organizes the setting up and commercial dissemination of the work: the Berne Convention allows national legislators to grant (as most in fact do) the rights of economic utilization of works created in an organized way, such as cinematographic works, 'to who organized the production of the work itself', i.e. the producer ${ }^{45}$ - analogous to the producers of phonograms; ${ }^{46}$

- similarly, the direct granting of 'neighbouring' exclusive rights to radio and television broadcasters; 47

- in contrast, the reference to non-commercial purposes (teaching, 'informatory': articles 10 and 10-bis Berne Convention), as proxy for legal 'free uses' of the copyrighted work (below, Chapter 3).

\section{Articles 64 and 65.}

43 According to said German law, in the case of inventions made during the course of employment the employee is obliged to inform thereof the employer, and the latter can refuse the invention (within four months) if he does not intend to use it - in such a case the invention becomes freely disposable by the employee. In the event that the invention is not refused, the invention is deemed to be accepted and the employer may patent it or use it in secrecy.

44 The UK Patent Act, as amended in 1977, provides (section 39) for an important exception to the employer's rights in favour of the employee if the invention has not been made under the contract of employment or in any case on the basis of a fiduciary duty: see W. Cornish, D. Llewelyn and T. Aplin, Intellectual Property: Patents, Copyright, Trade Marks and Allied Rights, Sweet \& Maxwell, 2013, 264 et seq. On the point at issue, UK law seems substantially convergent with the approach adopted long ago by the US Supreme Court 'where the contract of employment does not contemplate invention ... the right of patent belongs to the employee' (Dubilier, 289 U.S. 178, 1933).

45 See Berne Convention, article 14-bis.

46 See the international Convention for the protection of producers of phonograms against the unauthorized reproduction of their phonograms, Geneva, October 29, 1971.

47 Directive 93/83/EEC on the coordination of certain rules concerning copyright and rights related to copyright applicable to satellite broadcasting and cable retransmission. 


\section{(3) Regarding trademarks:}

- their intrinsic purpose 'of distinguishing the goods and services of an undertaking from those of other undertakings' (article 15 of the TRIPs Agreement), and think too of the rules on trademark licences, forfeiture through non-use (that is, non-use in commerce), extension of renowned signs' protection to 'not similar' fields of business, etc. (so too for other signs, such as the firm's name [individual or corporate] distinguishing the undertaking's business, and for signboards distinguishing shops).

Finally, by way of a common denominator among the various types of intellectual property rights, it should be noted that Directive 2004/48/EC on the enforcement of intellectual property rights expressly provides that the protection of economic rights against infringement is a matter for firms to take care of. This is partly because the amount of damages will depend on various profit indicators (of the right holder's and the infringer's firm) or because the injunction is specifically designed to further the interests of the right holder to oust the infringer from the market, preventing the latter from continuing or resuming its activities. It is also because in that normative context no mention is made of the author-person at all, not even, for example, to establish the principle of a right for the author to receive a share of the sum paid as damages equal to the percentage of its contractual royalty.

An equally pivotal role of the firm is emphasized by competition law(s) that, as hinted, often 'interfere' with IP's specific regime(s). This is true, at national and international level, of antitrust, directed at regulating behaviours and practices of business undertakings (or their associations) - likewise as regards unfair competition: see the reference of article 10-bis of the Paris Convention to the risk of creating confusion with or discrediting 'the establishment, the goods, or the industrial or commercial activities, of a competitor'. ${ }^{48}$

48 See sub-paras (1) and (2) of the third paragraph of article10-bis. See also the reservation of the standing to sue for unfair competition established in favour of entrepreneurial associations by article 10-ter of the same PUC. 


\section{Intellectual Property Rights as Enterprises' Tools to Improve Competitiveness}

While it is necessary for individual creators to alienate, as aforesaid, the economic rights associated with intellectual property to business undertakings so as to be able to economically exploit on a commercial scale the intangibles that they have created, it is likewise a typical - typically competitive - interest of firms, to be granted those rights as instruments of protection - in the terms and limits specified shortly - of their exploitative activities (productive and/or distributive) of the intangibles embodying technological and cultural innovation as well as means of information to the market (trademarks).

The degree of that interest varies depending on different economic factors, like, for example, the size and immobilization of investments in $\mathrm{R} \& \mathrm{D}$, or the level of competition in the market, the availability of, assumed to be, more convenient competitive tools, like advertising and marketing. Therefore, it is a typical but not 'necessary' interest - except as concerns trademark rights, the sole indispensable IPR in a competitive economy (below, Chapter 4, §1).

With this caveat in mind, one should not undervalue the specific role played by patents and ('techno' $)^{49}$ copyright protecting R\&D-oriented firms from the risk of actual or potential economic loss stemming from the activities of (economically significant) free riders/competitors (below Chapter 2).

In fact, apart from certain limited avenues, such as public subsidies ${ }^{50}$ or trade secrets, ${ }^{51}$ firms might not dispose of reliable tools to defend themselves against the risk that free riding by competitors will prejudice their chances of recovering costs and receiving remuneration for their

49 I.e. copyright on information technologies and industrial design works (Chapter 3).

50 More and more insufficient, in times of economic crisis, to cover actual costs; moreover subject to conditions and restrictions such as territorial or occupational limits, as well as to ambiguous trade-offs with the public administrations. The US Bayh-Dole Act 1980 grants federal agencies that have commissioned research with public monies the right to 'march in', that is, require the contractor who may be the holder of patents to grant a licence to third parties. See, inter alia M. A. Lemley, 'Are Universities Patent Trolls?', Fordham Intell. Prop., Media \& Enter. L J., 18, 2008, p. 611.

51 The possibility of exploiting technological results in secret is generally limited to process innovation. See below Chapter 2, $\S 21$ on the protection of secrets, traditionally granted by the rules against unfair competition. 
investments except through a (transferable) ${ }^{52}$ right to bar unauthorized parties from 'freely-and-gratis' accessing their intangibles, eminent factors of competitiveness. In an environment of free and direct competition between manufacturers of identical types of goods, the risk of suffering losses caused by the free riding of competitors may well overburden the innovator, who in such a market context already bears all other economic risks, beginning with the commercial failure of a new product. In the original argument put forth by Jeremy Bentham, ${ }^{53}$ who would fardels bear, i.e. who would invest in innovation if maverick competitors were free to reproduce the new inventions/creations immediately after the innovator had successfully launched them on the market? Having 'saved' on research costs, such competitors would enjoy a position enabling them to engage in a destructive, unsustainable price war.

The same basic rationale historically applies to copyright: the protection against economically significant free riding encourages ${ }^{54}$ publishers and other entrepreneurial players to invest in their industrial activities (as known, modern copyright originates from the new 'mass scale' printing techniques of Gutenberg and Manuzio ${ }^{55}$ ), as well as authors to professionally 'invest' their time and efforts in creative work, without depending on patrons' favours (below Chapter 3). ${ }^{56}$

Distinctly but similarly, only the firm's exclusive right on the commercial signs - trademarks, first and foremost - adopted to identify and distinguish its business and products, allows it to safeguard its corporate

52 Either in terms of entitlement/'ownership' or license of use. The exercise of the exclusive IP rights solely on the basis of licences was the focus of the US Supreme Court decision in eBay Inc. et al. v. Mercexchange LLC of 15 May 2006 (547 US, 2006). More below, Chapter 2.

53 Reference in fn 35, above.

54 By no coincidence, the protection against unauthorized copying of literary works was originally afforded to printing firms, commencing with the Renaissance library privileges. Only at a later stage (although in Venice since 1486) was such protection extended (by the Statute of Anne in 1710) from the incorporation of 'Stationers' as authors, that is, content providers, one might say, for the publishing business. On this point see L. Moscati, 'Alla radici del droit d'auteur', in F. Liotta (ed.), Studi di storia del diritto, Monduzzi Editoriale, 2007, 265. See also Histoire internationale du droit d'auteur des origines a' nos jours: numéro spécial a' l'occasion du vingtie'me anniversaire de la RIDA, Paris, 1974.

55 It is to Aldo Manuzio that we owe the birth of the modern book thanks to his development of the 'in folio' technique, which transformed the bulky volumes produced by Gutenberg's presses into items suitable for mass production/ consumption.

56 On this point, frequently ignored by straight 'no copyright' supporters, see below, Chapter 3 . 
identity/image from passing off by others and to exploit the associated goodwill in a competitive environment - and this, even in markets territorially quite remote from its seat and/or the place of production. Hence, it grants the firm the possibility to preserve its chances to continue receiving - for the entire period it operates on the market - the revenues flowing from consumers' preferential choice for its goods and services.

\section{THE SALIENT CONFLICTS OF INTERESTS UNDERLYING IPRs' EXERCISE}

\section{Conflicts between IPR Holders and Third Parties Claiming Access 'for Knowledge' or 'for Exploitation' of the Protected Intangibles: (i) Patents; (ii) Copyright; (iii) Trademarks}

The exercise of intellectual property rights, especially if realized - as is typical - by firms, gives rise to series of conflicts of interest (beyond those, evoked above, 'internal' to the relations between author, employee, entrepreneur), which constitute the fundamental key to understand the likely effects that the exercise of IPRs may produce versus the affected stakeholders. ${ }^{57}$ Accordingly, the recognition (by type, obviously) of such conflicts should be placed to avoid expressing a 'thought without roots' at the centre of any tentative in-depth reconstruction of the legal regime(s) of IP; a reconstruction that ultimately requires answering to the basic question - the eternal question! - 'who gains, who loses?'.

The panorama of conflicts is rather varied. Case law frequently highlights litigation between holders and third party defendants in relation to infringement claims or requests of declaration of nullity or

57 F. Cohen, 'Transcendental Nonsense and the Functional Approach', Columbia L. Rev., 1935, 810, at 811. On the relevance of the assessment of conflicts of interest in the analysis of IP law see J. O. Lanjouw and M. A. Schankerman, 'Enforcing Intellectual Property Rights', December 2011, National Bureau of Economic Research (NBER) Working Paper No. W8656, available at: http://ssrn.com/abstract=294094. Particularly on R\&D, see P. Samuelson, 'Innovation and Competition: Conflicts over Intellectual Property Rights in New Technologies', in V. Weil and J. W. Snapper (eds), Owning Scientific and Technical Information: Value and Technical Issues, Rutgers University Press, 1989, 169. 
lapse of rights - or others, revolving around contractual disputes between authors and inventors for one part and licensors and licensees for the other part.

Now, the private (inter-individual) nature of those disputes should not make us forget that their resolution normally projects itself on to a wider array of interests, even those of a collective character, hence invoking norms and principles of systemic rank. Just think of how the concept of 'equivalence' that arises in patent infringement actions can restrict or broaden the room for freedom of competition afforded to the followers of the rights holder. Or how the notion of 'derivative works' can broaden or restrict the sphere of contractual freedom of their authors when it comes to exercising their own copyrights.

A common denominator among the disputes in question can be identified in the dialectic between the exercise of IPRs' exclusive rights and the demands by third parties for access to the intangible assets protected by those same rights. There is an immanent dialectic between exclusion and access - access by those third parties who (different from sheer free riders) affirm their right to use the intangible asset either claiming the nullity or lapse of the entitlement or denying any infringement, or pretending to exercise a legitimate 'free use' or offering to pay a fair compensation for the use of same asset ('willing licensees').

In this perspective the salient distinction seems to relate to the objective purpose, i.e. function, of the access claims: more precisely, whether they are aimed at (merely) knowing 58 the protected intangible asset or at exploiting it on an industrial or commercial level.

As examples of the different types, by purpose, of access claims, just think, on the one hand ('access for knowledge'), of that related to the 'experimental use' of a patented invention, and on the other hand ('access for exploitation') of the claim for a licence from an IPR holder in a dominant position, as often supported, under article 102 TFEU by antitrust authorities and judges - as in the Microsoft saga (below Chapter 5).

These two basic different purposes are balanced by the legal system against the exclusionary interests of the right holder - in different ways and to varying degrees, as we shall see (Chapters 2 and 3) depending on whether patented inventions or copyright works are involved (or even, in

58 The concept of 'access for knowledge' includes inter-personal exchange of information - of course outside any industrial or commercial perspective (below Chapter 3, on copyright). 
atypical circumstances ${ }^{59}$ trademarks). Hence the need for a differentiated survey of the salient typical conflicts of interest in the field of IP: a survey obviously preliminary to the search for the appropriate guiding criteria for their solution (in this section and section VI).

\section{(i) Patents}

In relation to patents, the typical 'right vs. access' conflicts ${ }^{60}$ arise between holders and third party competitors, now tout court claiming on various grounds (typically, the invalidity of the IPR entitlement) their freedom to exploit the intangible goods, now requesting a licence.

In other words, the typical salient conflicts concern the claims to access for economic utilization, not for (just) 'knowing'. Indeed, the 'mere knowledge' profile is marginal and in any case secondary in patent-related conflicts. ${ }^{61}$ However, as patent law requires publication of the application accompanied by a description sufficiently detailed to enable a person of normal 'skill in the art' to implement the invention, this assures a public knowledge that satisfies both the interests for non-commercial purposes (typically, researchers' and teachers') and those for exploitative uses of the intangible asset (below Chapter 2, $\S \S 3$ and 20).

Also, patent disputes - typically, 'repeat', among competitors ${ }^{62}$ - tend to be individual in nature, an expression of economic struggle among private parties. But at the same time, those disputes normally touch on collective interests, be they economic (like the enhancement of innovation dynamics, or the preservation of a sufficiently effective degree of competitiveness in the market), or meta-economic (like the protection of health). And so, for example, a dispute focused on the scope of a patent that affects the sphere of competitors' freedom to develop an alternative solution does not remain a strictly private matter. The same can be said for the refusal to grant a licence to local producers in a developing

59 In particular, as concerns the use of trademarks in merely descriptive (not distinctive) functions: e.g. for labelling automobile spare parts produced by independent manufacturers. More below, Chapter 4.

60 More below, Chapter 2.

61 Consider also the secrecy period between date of filing and date of publication (below, Chapter 2, §§ 3 and 20). Moreover, of course, the holder can opt for secrecy instead of patenting (below, Chapter 2, § 21).

62 Except, maybe, those between employee-inventors and their employers. Perhaps, couldn't the employee-inventor be considered as a potential competitor (even as future collaborator of a competitor)? Isn't the discipline of employee's invention perhaps driven, at least in part, by the 'risk' of a competitively adverse use of the invention? 
country for the production of patented drugs for which no 'off patent' valid alternatives can be found.

\section{(ii) Copyright}

The panorama of conflicts of interest revolving around copyright appears more complex, especially vis-à-vis its expansion into technological sectors (below, Chapter 3).

(a) Let us first consider the contractual conflicts, in particular those between authors and publishers (in the broad sense). ${ }^{63}$ While some of such disputes - typically those about payment of fees - arise and develop within a purely economic inter-private perspective, others, like those concerning translations, new editions, reprints, new distribution channels, etc., can easily exceed that restricted ambit. These are economic conflicts, certainly; but quite often also touch upon both authors' moral interests and collective interest in the diffusion of culture and information. Think for example of a conflict focused on the denial, by a book publisher, of a licence to translate the work, or to have it printed and distributed by a 'willing licensee' third publisher in a low cost series of wide diffusion. Such denials, if unjustified by the quality of the translation or the reputation of the 'cheap' publisher, wound the author's legitimate interest in seeing his work circulate internationally, and at the same time affect the general interest in the popular spreading of culture and information. 64

(b) Other types of conflict arise - as for patents - from competitive relations, in particular among copyright holding firms and rivals interested to share in the exploitation of the protected works and/or to obtain the information relating to the reciprocal connection

63 I am referring to those that affect market relations: conflicts at merely inter-private level, like those concerning the amount of remuneration for authors, do not essentially pertain to IP law (below, Chapter 3). On a distinct plane, contractual conflicts between IPRs holders and licensees relate to e-commerce; and conflicts between holders and users related to social networks: see here C. McManis and B. Garrison, 'The Enforceability of Mass Market e-Commerce Licenses and Social Networking Agreements: Is Copyright or Contract Law the New Lex Specialis?' in G. B. Dinwoodie (ed.), Intellectual Property and General Legal Principles: Is IP a Lex Specialis? ATRIP Papers, Edward Elgar, 2015, p. 30.

64 On the protectionist evolution of the rules on translations from the original provisions of the Berne Convention to contemporary times, see Chapter 3 . 
between various products (for example, compatibility between computer software programs), in order to use that information for the development and sale of products that will compete on the same or downstream markets (for more see below, Chapters 3 and 5). Needless to say, even such conflicts are not merely 'private', since the effects of their resolution project into the market's competitive fabric, as well as on the dynamics of innovation.

(c) Last but not least, there come 'societal' conflicts: namely those between copyright holders and non-competing third parties: a vast arena of social stakeholders, holders of essentially non-economic interests, who seek access to copyright works for knowledge purposes: study and research, teaching, public debate. Interests that, again, clearly touch also objectives of constitutional rank (below, Chapter 3).

Typically, conflicts of this type are shaped by the different business models adopted by copyright holders for meeting the demand of access. I refer to the well-known dichotomy between traditional models based on direct compensation from the users, i.e. paying schemes enforced by contractual clauses and encryption devices, and 'open' models granting 'free' (seemingly free: access to the users while indirectly deriving revenues from the advertising and other services accompanying the 'free' diffusion of said copyrighted work (below, Chapter 3). ${ }^{65}$

\section{(iii) Trademarks}

Less frequently, conflicts of interest arise also in relation to access to distinctive signs and especially trademarks between the right holder and third parties (not, repeat, straight infringers).

Also in this field, what is at stake is not the profile of knowledge, since a trademark is by definition a conveyor of information (it 'carries the information on its surface', to borrow Jerome Reichman's famous remark about computer programs). Thus, the demand for access by other entrepreneurs, competitors or non-competitors, however, interested in adopting a renown, attractive, commercial sign, entirely revolves around the economic exploitation of the distinctive sign. Again, such conflicts cannot be viewed as merely private: they, and their resolution, can have relevant impact on such general interests as freedom of competition and protection of commercial good faith (i.e. consumer trust). Just think, for

65 Think for example of the Oracle/Google dispute: on first degree, Oracle America, Inc. v. Google, Inc., 872 F.Supp.2d 974 (N.D. Cal. 2012), and - on appeal - 750 F.3d 1339 (Fed. Cir. 2014). 
example, of conflicts triggered by an action enforcing the allegedly deceptive use of a trademark; or by an attempt to exclude third parties from the use of a descriptive sign, or to prevent the use of a similar sign even in the total absence of any apparent connection between the firms concerned.

\section{A Brief Caveat against the Risk of Schematism in Assessing Interests and Conflicts}

Very briefly: in assessing and comparing private to collective interests, jurists and economist alike should avoid rigid 'unidirectional' schemes and juxtapositions. As already hinted apropos of editorial conflicts, certain private interests can run in parallel with collective ones or with different private interests - meaning, those of parties other than the IPR holder. Think of another example: that of the 'exception' to a patentee's rights represented by the experimental use of the invention. Here, certainly, the interests of the researcher and that of the patentee are confronting each other, and the law privileges those of the former. But are we sure that such interests are always and necessarily colliding? Might it not be that the freedom of the researcher ends up providing the patent holder with information useful for future improvements to the original invention? Or might it not be that the results of the researcher's activity provide the basis for third parties' successful oppositions to the granted patent, thus removing from the path of subsequent developers an 'undeserving' legal barrier?

'There are more things ... Horatio ...'.

\section{A Wider Panorama of Societal Interests}

A movement of (so far) mostly academic opinion, acting on an international scale, is progressively broadening the picture of the interests, and related conflicts, revolving around the protection of intellectual property. I am referring to interpretative proposals aimed at 'hybridating' IP law with an array of societal issues traditionally foreign to its boundaries, well beyond competition- and/or consumer-welfare-related issues. I refer to protection of the environment, health, nutrition, privacy, and human rights tout court. A series of intriguing suggestions have been advanced aimed at adapting or modifying regimes of IPRs (mainly those of patents and copyright, less so trademarks) in order to foster collective interests in the said 'new' areas.

Here, a critical eye might suggest exploring if and to what extent said proposals might objectively end up attributing to IP law functions and 
'responsibilities' that should perhaps more properly and wisely (also in the sense of 'efficiently') be primarily entrusted to ad hoc public regulation (for more see below, Chapters 2 and 3). In other words: let's give to Caesar ...

Please, don't get me wrong here. I look at that movement of thought, as hinted, with highly empathetic interest as one of the most significant and nobly inspired developments of contemporary research in IP - as a development that pushes forward the frontier of IP law to a "wider legal landscape' 66 than that traditionally considered by a Zeitgeist largely inspired by vested business interests. ${ }^{67}$

\section{FROM ECONOMIC CONFLICTS TO THOSE BETWEEN LEGAL MODELS}

\section{The Contrast between Protectionist Tendencies and 'Pro-dynamic' Ones}

Intuitively, conflicts directly or indirectly underlying the exercise of intellectual property rights often mobilize huge resources and deeply impact on the fate of businesses, the well-being of consumers and users, the production and spread of culture and information, and even certain profiles of citizens' rights - just think of health and privacy. Thus, such conflicts constitute the real terrain where normative and interpretative stances of opposing legal and political hue clash - often in the tones of wars of religion. In their turn, such stances constitute as a whole the state of the art of the contemporary debate of international range about intellectual property law. So, at this juncture of the discourse, it is worth attempting a summary reconstruction of those conflicting stances, and their underlying fundamental ('structural', I am tempted to say) economic rationale.

\section{Protectionist Trends}

As they have been established for longer among lawmakers and judges, and with an influence that is still predominant even if no longer

66 A. B. L. Brown, IP, Human Rights and Competition: Access to Essential Innovation and Technology, Edward Elgar, 2013, p. 22.

67 'Was Ihr den Geist der Zeiten heißt, das ist im Grund der Herren eigner Geist, in dem die Zeiten sich bespiegeln' (Goethe, Faust, Eine Tragoedie, I, 578-580; emphasis added). 
hegemonic, I will first deal with the trends that Jerome Reichman famously labelled as 'over- protectionist'. Trends vigorously promoted worldwide from across the Atlantic - a sort of Washington consensus in IP - that both in general terms and in relation to specific principles and industries, substantially shift the centre of intellectual property law further towards the pole of exclusion/monopoly rather than that of access/freedom. And hence privilege the interests of current holders of intellectual property rights - especially the dominant ones - compared with those of third parties - competitors, researchers, users, 'common' citizens.

In modern times, the protectionist trends have expressed themselves along three main lines:

(i) The extension, under various teleologically convergent aspects, of the scope of the protection (hence power of exclusion) afforded by exclusive rights. The protection of trademarks has been expanded beyond the limits traditionally set by the distinctive function, 'leveraging' in business sectors 'not similar' and at times even remote from those in which the trademark holder operates. Moreover, as concerns patents, in some jurisdictions, as in the US, the scope of the patent has been interpreted as including even possible alternatives to obtain the same end-product (compare this approach with the opposite European one, for example in the Amgen cases, where the British House of Lords acknowledged the 'monopoly' only on specifically claimed elements). ${ }^{68}$

(ii) The replacement, in the industrially strategic sector of ITs, of patent protection, richer in pro-competitive antibodies (below, Chapter 2), by the copyright regime, which features a more intense promonopolistic bent (below, Chapter 3). ${ }^{69}$

68 Compare: (a) US District Court, D. Massachusetts, Amgen Inc. v. Hoechst Marion Roussel Inc. et al., 339, F. Supp. 2d 202, 2004, upheld on this point by US Ct of App. for the Fed. Circ., 457 F. 3d 1293, 2006; and (b) UK House of Lords, Kirin-Amgen v. Hoechst Marion Roussel Ltd, session 2003-2004, available at: http://www.publications.parliament.uk/pa/ldjudgmnt/jd0410221/kirin1.htm.

69 May I also refer to the denial, in the US, of the applicability of the 'research exception' to those who operate in a business environment. And this, not only within a firm's laboratories: according to Madey v. Duke University (307 F. 3d 1351, Fed. Cir. 2002) even research activities conducted within a university might not benefit from the experimental use exception because they are motivated by commercial interests. 
(iii) As far as copyright is concerned, the main historical example is of course the extension of the copyright term, progressively lengthened to the current term of 70 years from the death of the author (see Directive 2006/116/EC, ${ }^{70}$ amended by Directive 2011/77/ $\mathrm{EU}^{71}$ ), and also extended to cover related rights. Moreover, Directive 2001/29/EC on copyright 'in the information society' (InfoSoc: Chapter 3) established new forms of protection based on the legal enforcement of anti-infringement technological devices as well as new judiciary barriers (the 'three-step-test') capable of reducing in the digital sphere the already limited scope for 'free uses' (the term used by the Berne Convention, now downgraded through lexical ploys that are not merely formal to the rank of 'exceptions and limitations') of works, data, and information covered by copyright or 'neighbouring' rights.

Last but not least, there is the recent Commission's Proposal to introduce, by a new Directive (expected in Spring 2018), ${ }^{72}$ a new so-called 'ancillary' right (in truth, a 'shorter' copyright) of newspapers and magazine publishers, allowing the same to prohibit the extraction and online publication, ${ }^{73}$ for editorial uses, of parts - even very short fragments ('snippets') - of published articles; thus adding further constraints to the already circumscribed freedom to access and circulate information (below, Chapter 3, § 18).

70 Directive 2006/116/EC of the European Parliament and of the Council of 12 December 2006 on the term of protection of copyright and certain related rights (codified version), OJ L 372, 27.12.2006, amended and replaced Council Directive 93/98/EEC of 29 October 1993. Likewise in the USA a further copyright term extension - to 105 years - was granted to corporations: see Copyright Term Extension Act 1998, also known as the 'Sonny Bono Copyright Term Extension Act', adopted in the run-up to the expiry of the protection period for the first Disney cartoons.

71 Directive 2011/77/EU of the European Parliament and of the Council of 27 September 2011, OJEU L 265/1 of 11 October 2011. That Directive not only extended the term of protection for fixation of a performance and phonograms to 70 years after the performance of first publication, but also harmonized the duration of protection for musical compositions with words in cases where the music and words are by two different authors.

72 Proposal for a Directive on 'Copyright in the Digital Single Market' of 14 September 2016 is available at https://ec.europa.eu/digital-single-market/en/news/ proposal-directive-european-parliament-and-council-copyright-digital-single-market.

73 See below, Chapter 3, § 19. 
On a separate but related point, see the extension to trade secrets' protection of the system of enforcement (sanctions, discovery, etc.) provided for IPRs (below, Chapter 2, § 21). Witness also the repeated, at times surreptitious, attempts to include within the scope of intellectual property law the protection of types of creation which, whilst linked to innovation-generating processes, have traditionally been considered to fall into the public domain and therefore be open to free competition. Some examples are the recurrent proposals regarding the 'propertization' of data that threaten, inter alia, to erode the principle of the free use of the results of basic scientific research. ${ }^{74}$ Let me also recall the quite ambiguous prospect of considering the expression of diverse local cultures (so-called 'traditional knowledge' and folklore) as apt subject matter of intellectual property rights: a prospect which if not governed by wise specific regulation could lead to the privatization of elements that should properly be qualified as cultural domain. ${ }^{75}$

74 On this issue, see the persuasive Position Paper by J. Drexl, R. M. Hilty, L. Desaunettes, F. Greiner, D. Kim, H. Richter, G. Surblyt, and K. Wiedeman, 'Data Ownership and Access to Data. Position Statement of the Max Planck Institute for Innovation and Competition of 16 August 2016 on the Current European Debate', Max Planck Institute for Innovation and Competition Research Paper Series, August 2016, Monaco. See also J. Drexl, 'Designing Competitive Markets for Industrial Data - Between Propertisation and Access', Max Planck Institute for Innovation and Competition Research Paper Series, October 2016, Monaco; and Bird \& Bird, White Paper, Data Ownership in the Context of the European Data Economy: Proposal for a New Right, available at https://sites-twobirds.vuture.net/1/773/landing-pages/white-paper-form.asp. Already in 1997, J. H. Reichman and P. Samuelson ('Intellectual Property in Data?', Vanderbilt L. Rev., 1997, 51) proposed the introduction of compulsory licences for extracting information from databases.

75 See here: R. Coombe, 'Fear, Hope, and Longing for the Future of Authorship and a Revitalized Public Domain in Global Regimes of IP', DePaul L. Rev., 2003, 1171. I totally agree with the proposal to introduce a sort of misappropriation right (fully compatible with the domain principle) to protect indigenous communities against the misappropriation of their biodiversity and associated traditional knowledge. I am referring in particular to documents currently being drawn up by WIPO: http://www.wipo.int/edocs/mdocs/tk/en/ wipo_grtkf_ic_18/wipo_grtkf_ic_18_5.pdf. Regarding the problem referred to in the text, I believe they should be denied any possibility to occur by the pro tempore representatives of communities at all levels, whether villages or entire countries, alienating assets that belong to the community itself in a historicalinstitutional sense, such assets constituting cultural heritage in the public domain: see article 822 of the Italian Civil Code. What it should be possible to grant are temporary licences to use said cultural assets in a manner and according to terms capable of preserving their integrity and defending their dignity and 
Moreover, two recent EU legislative initiatives seem to add fuel to the worries about pro-oligopolistic drifts, as such favouring the strongest players. The first of these is represented by the institution (not yet actually implemented: see fns 8 and 9) of the 'unitary patent' and related Unified Patent Court. ${ }^{76}$ While the declared aim is pro-competitive, the actual features hint towards a marked favour for the major patent holding firms. While the only significant advantage for SMEs seems to be that of a simplification and consequent reduction of costs for obtaining a single patent valid throughout the European Union, the architecture of the new model appears so complicated as to objectively forbid the effective enjoyment of substantial benefits by SMEs. On one side, the European legislator has articulated, i.e. fragmented, the discipline along different normative sources - and corresponding types of patents (national, EU, EPC, a crowded bed indeed) - plus, as regards litigation the new jurisdiction established by the aforesaid Agreement on the Unified Patent Court. Add to this the lack of anti-monopolistic antibodies, in primis compulsory licences (an item 'abandoned' to the discretion of national legislators) that will adversely affect innovation-oriented SMEs. On the other side, as concerns the aforesaid rules on litigation established by the Agreement on the Unified Court, the promotion of common jurisdictions seems designed to serve those players capable of utilizing a system of high complexity and specialization, and concentrated in costly international fora: a system, then, basically within the financial reach of the happy few. Thus the new 'unitary patent' will most likely help to build a further position of competitive advantage for the benefit of the major not necessarily European - patent holders: a position that these will be tempted to use in order to further strengthen their market power.

The second EU initiative is represented by Directive 2014/26 regulating the activity and powers of copyright collecting societies. Again, the

reputation. On this highly sensitive issue, see amongst others, N. Mezghani, 'La protection du folklore, des créations populaires ed du savoir traditionnel', in G. Ghidini and L. M. Genovesi (eds), Intellectual Property and Market Power ATRIP Papers 2006-2007, Eudeba, University of Buenos Aires, 2008, 313. On this topic see also M. Blakeney, 'The Negotiations in WIPO for International Conventions on Traditional Knowledge and Traditional Cultural Expressions', in J. C. Lai and A. Maget Dominicé (eds), Intellectual Property and Access to Im/material Goods, Edward Elgar, 2016, p. 227; S. Frankel, 'Ka Mate Ka Mate, and the Protection of Traditional Knowledge', in R. C. Dreyfuss and J. Ginsburg (eds), Intellectual Property at the Edge: The Contested Contours of IP, Cambridge University Press, 2014, 193.

76 EU Regulations 1257 and 1260/2012 (substantive discipline) and Agreement on Unified Patent Court (judicial procedure). 
declared purposes are convincing: enhancing such entities' professional skills and overcoming the so-far nationally partitioned management (as an alleged consequence of copyrights' 'territoriality') of a type of 'material' of intrinsically universal - however transnational - value. But again an adverse effect might occur, as the overall architecture of the new system objectively privileges, as has been noted, the role and actions of stronger societies, now i.a. facilitated - even by the provision of multi-territorial licensing schemes - in pushing weaker companies to the margins (below, Chapter 3, § 21).

\section{Specifically Concerning TRIPs' Impact on Developing and Least Developed Countries}

Last, but certainly not least, let us discuss a geopolitical profile evoked by the TRIPs Agreement. ${ }^{77}$ As already hinted, TRIPs' rules basically reflect the established IP regulation of industrially developed countries, the main holders of technology and innovative production techniques. And it is no secret that the Agreement was strongly advocated by the said countries, even with specific intense diplomatic support ('knowledge diplomacy') for the proposals and requests of major industries belonging to the International Intellectual Property Alliance.

This being beyond discussion, worthy of emphasis are some specific normative features that TRIPs adopted (and imposed, even by the tying clause of WTO membership) ${ }^{78}$ for the objective effect of strengthening the position of developed countries in a framework of international competition marked by the role of immaterial assets - the primary source of the wealth of nations in the 'knowledge economy'. In particular, said features appear apt to worsen the position of Developing Countries (DCs), and particularly of the Least Developed Countries (LCDs: as defined by article 66 TRIPs).

77 On the ensuing bilateral or regional ensuing agreements - so-called TRIPs plus - a policy inaugurated by the US even prior to TRIPs, see below, fns 82 and 84 , and accompanying text

78 In order to have the highest number of nations toe the line, adhering to the TRIPs Agreement was made a pre-requisite for membership of the World Trade Organization (WTO), the multilateral board of international trade which was established (as a replacement for the General Agreement on Tariffs and Trade [GATT]) on the same date as the TRIPs Agreement. Also well known is that in pushing for the realization of the TRIPs, the US aimed to incorporate many of the conditions that they had previously successfully negotiated in bilateral agreements with less developed countries, thereafter presenting the draft Treaty as an expression of 'harmonization'. 
Let us now consider, separately and in their synergy, two such features which usually attract less attention. Then, I will attempt to explore if, how, and to what extent the overall system of the Agreement can provide room for reducing their apparently negative impact on the position of DCs and LDCs.

However, before, beginning my analysis, I must enter a couple of caveats.

First, the dynamics of economic integration continuously work to alter existing equilibria - and disequilibria. Thus, the very definition of a country as developing cannot be assumed rigidly: the emerging group of 'technologically proficient developing countries'79 offers evidence of different speeds of development. China, India, Brazil and others are to different degrees and in different ways engaged in often highly advanced research and development (R\&D) activities. Moreover, and thanks also to intense manufacturing 'delocalization' - the typical feature of contemporary 'globalization' - such countries are emerging, in different ways, also as partners - at times even the dominant partners (think about the Lenovo-IBM deal) - of established Western and Japanese firms: firms with which, maybe, the former had been at odds for years over IP-related conflicts. Thus, the hope is that the ongoing technological progress and international economic integration of several developing countries will act in synergy with the general decline of 'unilateralism' in international relations. ${ }^{80}$ Such hope, however, is counterbalanced by the observation, ${ }^{81}$ on one side, of how major emerging countries seemingly assess their own geopolitical interests as concerns IP, i.e. by powerfully strengthening their national IP infrastructures (e.g. China has built the world's largest Patent Office), instead of acting as drivers for the progress of the less developed (in other words, 'forgetting their own past' and objectively coalescing with the developed world) and, on the other side, of the all too evident lack of organized initiatives by the overall group of DCs and

79 S. Basheer, "The "Glivec" Patent Saga: A 3-D Perspective on Indian Patent Policy and TRIPS Compliance', in ATRIP Papers, 2008, at: http://www. atrip.org.

80 Less than ten years ago Graham Dutfield ('Knowledge Diplomacy and the New Intellectual Property Fundamentalism', in J. Malbon and C. Lawson (eds), Interpreting and Implementing the TRIPS Agreement: Is it Fair?, Edward Elgar, 2008, 31 ff.) asked, 'Will the United States government be so pro-patent when the proportion of domestic patents granted to Indian and Chinese inventors increases dramatically?'.

81 P. Drahos, 'The U.S., China and the G-77 in the Era of Responsive Patentability', Queen Mary J. of IP, 2012, 315 ff., in particular 323 ff. 
LDCs for uniting forces to elaborate and build alternative legal frameworks, better suited to their own necessities of development. Thus, in conclusion, the acknowledgement of the progressive shift of the economic status of some formerly DCs (the BRICs) towards the level of the developed ones, cannot cancel the persistent reality of so many countries (in Africa, first and foremost, but not only there) as one of enduring struggle to achieve a reasonable technological standard in vital sectors. The reality of LDCs, in particular, highlights that the problem of a large 'asymmetry' of terms of trade, as possibly enhanced by the TRIPs Agreement, is far from being overcome. The second caveat focuses on the comparative assessment of TRIPs and the hinted plurilateral (sometimes regional) agreements, and above all bilateral ones - so-called Free Trade Agreements (FTAs), ${ }^{82}$ also referred to as TRIPs plus. As often remarked, the TRIPs' multilateral character and 'administrative' system (in particular as regards the resolution of disputes) translates into a relatively more balanced regulatory structure, which can impose some limits on developed countries' capacities to easily impose harsher conditions on developing countries (DCs), while offering room for interpretation also aimed at mitigating the inherent disparity in bargaining power. ${ }^{83,84}$

82 For a lucid assessment of this type of agreements, see the Max-Planck Institute's project 'Principles for IP Provisions in Bilateral and Regional Agreements'. The 'Principles' are introduced by its coordinator H. Grosse Ruse-Khan, in IIC vol. 44, n.8, December 2013, also at: http://www.ip.mpg.de/files/pdf2/ Principles_for_IP_provisions_in_Bilateral_and_Regional_Agreements_final11. pdf. See further, ex multis, H. Rangel Ortiz, 'Sensitive Health and Patent Law Issues in Bilateral Agreements Recently Executed by the United States - the Latin American Experience', in G. Ghidini and L. M. Genovesi (eds), Intellectual Property and Market Power - ATRIP Papers 2006-2007, Eudeba, University of Buenos Aires, 2008, 367.

83 It must be borne in mind that the declared ambition of the TRIPs Agreement was that of 'deep integration' - harmonizing the policies and laws of developing countries with those of the global community - initiated by American multinational corporations and foreign policymakers: M. D. Ryan, Knowledge Diplomacy, Brookings Institution, 1998, 141. On the exceptions to exclusive IPRs allowed by TRIPs see E. B. Rodriguez, The General Exception Clauses of the TRIPS Agreement, Cambridge University Press, 2015.

84 See in particular, H. Rangel Ortiz, 'La propiedad industrial en los acuerdos comerciales de las Américas del siglo XXI', Concorrenza e mercato, 2007, 273. As an example, consider that the extension of copyright term to the life of authors plus 70 years has been imposed in several FTAs without the balancing factor of the rules on 'fair use' (G. Dutfield, 'Knowledge Diplomacy and the New Intellectual Property Fundamentalism', in J. Malbon and C. Lawson 
On the contrary, that disparity is notoriously enhanced in the hinted at more restrictive regional and especially bilateral Agreements (TRIPs plus) in which the truth of Aesop's fable about the lamb and the wolf is only too well borne out.

Let us now discuss the two specific normative features of TRIPs that I consider a significant expression of colonialism by other means; namely, (a) the deadlines for applying TRIPs rules and (b) the repeal of the (industrial) local working requirement for enjoying patent protection.

(a) The TRIPs Agreement (article 65) obliged developing countries to apply its provisions within a short period (very short from a historical perspective: five years from the signing of the WTO Agreement) that is furthermore fixed and equal for all - save for a limited (from a historical perspective) delay of a further five years (article 66) in favour of the least developed countries - this term being further extended in 2001 in Doha to 2016 , then to 2033 as concerns pharmaceutical product patents. ${ }^{85}$

Let us dwell for a minute on the geopolitical significance of this unification of models and timing, especially as regards timing. It seems to me that in this way today's industrialized countries have 'done unto others' what they themselves refused to accept could be 'done unto them' in the initial stages of their own industrial development. As is well known, today's industrial powers themselves determined, based on their own stage of development, how and - above all - when to apply strong models for the protection of intellectual property.

For example, at the beginning of the 19th century the German states were considered by France as havens for plagiarists. Germany introduced legislation against unfair competition between the end of the 19th and the beginning of the 20th centuries, when it recognized that it could afford the 'luxury of fairness'. ${ }^{86}$ May I also recall that before its rapid industrial reconstruction after World War II, Japan was famous for its capacity to ('kodak' and) copy almost everything.

(eds), Interpreting and Implementing the TRIPS Agreement: Is it Fair?, Edward Elgar, 2008, 31).

85 However, the Council for TRIPs may, upon duly justified request by a least developed country member, grant further extensions.

86 'Die deutsche Industrie steht heute auf einer solcher Höhe, sie ist so reich und kräftig, das sie den Luxus der Ehrlichkeit gestatten kann', said the distinguished German jurist Wassermann, in a speech given in Berlin, in 1912, on the occasion of the constitution of a commission for the study of indications of origin (source: L. Coquet, Les indications d'origine et la concurrence déloyale, Paris, 1913, 317; emphasis added). 
As for the US, current champion of the need for stringent protection of intellectual property, Professor Jane Ginsburg87 reminds us that its publishing industry grew and flourished thanks to the unauthorized copying of the works of English and Irish authors (Dickens's exasperated protests have remained famous). And this went on until the end of the 19th century, when the American publishing industry eventually produced 'enough' successful own authors to 'sell' even on the international market (think of Hawthorne, Melville, James, Thoreau, Emerson, Whitman, Alcott, Fuller, etc.), thereby eventually accepting the principle of reciprocal international copyright protection. ${ }^{88}$

The less said about Italy the better. Suffice it to say that the industries of my country's northern regions claim protection (especially in the fashion and musical recording sectors) against counterfeited goods, many of which are produced in and/or imported from the southern regions, under the efficient supervision and management of the mafia(s).

Thus, in the final analysis, those deadlines, accepted willy-nilly by developing countries for applying Western models of IP protection, objectively risk 'sticking' those same countries in the disadvantaged economic situation mentioned above - precisely because the value of high-tech products that, in international exchanges, flows from the protection of IPRs, mostly relates to the production 'of the others'.

'No, the contrary is true!', outright supporters of the system proclaim. Quick legal unification tends to speed up recourse to R\&D by developing countries, they say. Those optimists argue that a healthy lash of the whip will help backward countries to escape their long dependence on the primary sector, as well as the clutches of technological stagnation. It is a serious objection, certainly convincing when it refers to relations between

87 J. C. Ginsburg and J. M. Kernochan, 'One Hundred and Two Years Later: The U.S. Joins the Berne Convention', in R. P. Merges and J. C. Ginsburg (eds), Foundations of Intellectual Property, New York, 2004, 298 et seq.

88 Moreover, even under those circumstances, the Chace Act 1891, which acknowledged foreign authors' and publishers' copyright - and which remained in force for decades - granted such protection on condition that foreign texts were printed in the US (a local working requirement, indeed), even banning the import of editions published abroad - as the Venetian authorities had done in the late 15 th century in granting privileges related to books and printing aimed at fostering the growth of a domestic publishing industry after the emergence of the new technology of printing. See here B. Bugbee, Genesis of American Patent and Copyright Law, Washington DC, 1967, at 43-44. 
industrially developed countries. ${ }^{89}$ But as regards relations between developed and developing countries, that objection draws no comfort from experience, except to a very limited degree, and in any case contradicts its underlying assumption.

In fact, the prophesy of the healthy whiplash has started to come true solely for those developing countries (BRICs in particular) whose levels of industrial investment have enabled them to marshal sufficient resources to give birth to technically complex productions. More significantly, however, the countries in question have reached or are on the verge of reaching that capacity also thanks to a previous refusal - and not a previous acceptance! - of strong intellectual property protection models.

In short, these emerging countries have objectively done what today's industrialized countries did in the 1800s and part of the 1900s when they effectively ignored or got around IPRs until their own industries were no longer in their infancy. By contrast, the same countries started to effectively observe and respect IPRs as soon as they in turn became producers of advanced technology (often acquired through imitation), and it was then in their interests to adopt a policy of safeguarding intangible assets in domestic and above all international trade. Every country, substantially, has done so in the initial stages of its development. Cosi fan tutte.

(b) The second normative feature I consider an expression of neocolonialism through IP law, refers to the patent regime, and highlights a relevant development introduced by the TRIPs Agreement specifically concerning the international diffusion and circulation of technologies.

I am referring to the repudiation, expressly sanctioned by article 27.1 of the TRIPs Agreement, of the historical principle (enshrined in the Paris Convention 1883, article 5A.2, and adopted by the vast majority of the emerging industrial states of the 19th century) that allowed Member States granting a patent to request that said patent be (industrially) worked in situ (the so-called local working requirement [LWR]). ${ }^{90}$ The

89 Relations which at times, however, can themselves be highly conflictual: just think of the disputes about denominations of origin of typical agricultural produce (like Parmesan).

90 Article 5.A of the Paris Convention, incorporated in the TRIPs Agreement via article 2.1 TRIPs, allows member countries to require a patentee to produce the patented goods in the country where protection is sought if the country issuing a patent so desires, and treats a failure to work the patent locally as an abuse of the patentee's exclusive rights. On the other hand, article 27.1 TRIPs makes 'patent rights enjoyable without discrimination as to the place of invention 
obvious objective and rationale was the fostering of technology sharing and thus the acceleration of domestic industrial growth.

Historical principle, indeed. Long before the 1883 Universal Convention, it had characterized the very early stages of Western economic development. Already in late medieval and Renaissance Europe, privileges and franchises (the ancestors of modern patents) were issued primarily to induce the transfer, even by mere import, of foreign technologies. ${ }^{91}$ This policy was shared inter alia by early American legislators. Addressing Congress on 8 January 1790, George Washington called for legislative attention to IP, 'giving effectual encouragement, as well to the introduction of new and useful inventions from abroad, as to the exertions of skill and genius in producing them at home'. ${ }^{92}$

Let us now return to today's economic and legal scenario. The repudiation at the very end of the 20th century of the local industrial working requirement had for a long time been advocated by dominant business circles and conceived in general terms (not just in connection

... and whether products are imported or locally produced'. The need to reconcile these two provisions has led scholars like J. Straus ('Implications of the TRIPs Agreement in the Field of Patent Law', in F.-K. Beier and G. Schricker (eds), From GATT to TRIPs, in ICC, 1996, 18, p. 204) to assume that WTO Members can no longer consider patentees' failure to work a patent locally as a per se abuse. They would commit such abuse (and thus become subject to a compulsory licence under the same article of the Paris Convention) only if they should undersupply the country that granted the patent, that is, they would not provide, even by mere exports, enough products to the country itself. Albeit not universally shared (see, for example, J. H. Reichman and C. Hasenzahl, Nonvoluntary Licensing of Patented Inventions: Historical Perspective, Legal Framework under the TRIPS Agreement, and an Overview of the Practice in Canada and the United States, Draft, UNCTAD/ICTDS, 2002, II, C.2), even such an interpretation - upholding the repeal of the local working requirement can be reconciled with our argument and thesis. The former indeed provides for a general rule, while the latter refers to a 'limited exception' in the meaning of article 30 TRIPs.

91 Thus, under Elizabeth I, many 'monopoly rights' were granted for that very purpose, such as that granted to two foreigners to introduce the manufacture of hard white Spanish soap, and another for the manufacture of saltpetre - a component of explosive powders - previously imported from Antwerp. See J. Federico, 'Origin and Early History of Patents', J. of the Pat. Off. Soc., 1929, II, 293-297.

92 Quotation from Paul A. David, 'The Evolution of IP Institutions and the Panda's Thumb: Patents, Copyrights, and Trade Secrets in Economic Theory and History', in Global Dimensions of Intellectual Property Rights in Science and Technology, National Research Council, 1993. Nineteen other essays by Professor David are quoted in the Bibliographical Notes at the end of this chapter. 
with developing countries) as a means of supporting 'industrial freedom' (freedom of choice of industrial setting) at an international level. Now I submit that, situated within the contemporary framework of relations between developed countries - that is, countries that have already achieved industrial maturity and are endowed with sufficient financial means to invest in technology-driven competition - the repudiation of said requirement represents a reasonable anti-protectionist stance. At that stage of development, indeed, the requirement implied greater costs in terms of freedom of industrial establishment than benefits in terms of local transfer of technology.

However, I doubt that this is equally true of relations between such countries and developing countries. In this context, the abandonment of the requirement to work the patent locally curtails the spill-over of advanced technological skills, and hence the sharing by developing countries of the R\&D processes, capacity and production knowledge 'housed' within the patents (and the know-how that typically accompanies them). Hence, at the stroke of a pen, the international protection of IPRs has lost a decisive instrument and driving force in assisting developing countries to bridge the gap with advanced countries - an instrument that industrially advanced countries largely employed in the past precisely to enhance, to their own benefit, the sharing of technological knowledge. See, for example, in article 53 of the previous Italian Patent Act, in force until 1996, to the effect that 'the import into or sale in the State of objects produced abroad does not constitute working of the invention'.

Again, a double standard.

Now, the objective synergy between the two above-mentioned features may entail a risk for developing countries - and especially for LDCs that a brake will be put on their chances of industrial development, hence their ability to effectively compete on the world market. In other words, they risk remaining 'stuck' even longer in their role as mere importers of patented technology against which they exchange semi-processed raw materials and products with a low technological content. A colonial scheme, it appears.

What might be the remedies? The tentative answer must focus on solutions that might be introduced de lege ferenda, as explicit reforms to the present legal framework. Indeed, under the two profiles we are discussing, the norms text (articles 65 and 66 [integrated by the Doha resolution] and article 27.1) is so clear and univocal that it allows no 'redeeming' interpretation, however grounded on a sound economic rationale and systemic arguments. Thus, as concerns the 'time schedule', one might first of all propose that current LDCs (whose official listing is 
of course 'fluid') be bound to adopt TRIPs rules, not at a standard, one-size-fits-all date, but on an individual basis, as each different country reaches an objective level of economic development, measured by a bundle of objective indexes, such as per capita income, basic infrastructural assets, export/import balance, gross national product (GNP), etc.

Then, as concerns the LWR, the 'Doha exception' should be widened beyond the pharmaceutical sector, thus allowing LDCs to require local industrial working of patents until they overcome the status of LDCs.

Systemic (and textual) arguments press in this direction.

Let me start by recalling a couple of TRIPs' 'general provisions and basic principles' (Part I General), namely: (a) that 'protection and enforcement of IPRs' is not an end in itself, but rather a means to 'contribute to the promotion of technological innovation and to the transfer and dissemination of technology' (article 7; emphasis added); and (b) more specifically (and logically connected), that 'Members may, in formulating or amending their laws and regulations, adopt measures necessary ... to promote the public interest in sectors of vital importance to the socio-economic and technological development' (article 8; emphasis added).

As 'basic principles' - clearly and strongly highlighted by WIPO's in-progress 'Development Agenda' 93 - these rules should also guide the assessment and definition of the type and scope of 'measures' that the system of TRIPs allows Members to adopt when the need arises to conciliate IPRs holders' 'legitimate interests' with third parties' equally 'legitimate interests' (article 30).

And here, of course, one immediately thinks of articles 30 and 31: that is, respectively, of the possibility to 'provide limited exceptions to the exclusive rights conferred by a patent' ('provided that such exceptions do not unreasonably conflict with a normal exploitation of the patent and do not unreasonably prejudice the legitimate interests of the patent owner'), and to the possibility of allowing 'other uses' ('other' being different from the measures envisaged in article 30: see official note to article 31) 'of the subject matter of a patent, without the authorization of the right holder, including use by the government or third parties authorized by the government' - thus: 'government use' and 'compulsory licences' (article 31).

93 See in particular recommendations Nos. 19, 25 and 28 adopted by WIPO's General Assembly in 2007, on the basis of the proposals by the Provisional Committee on Proposals Related to WIPO Development Agenda (at http://www.wipo.int/ip-development/en/agenda/recommendations.html). 
At this point, I submit the following argument: that the imposition of a local working requirement inflicts a much more limited restriction on the patentee's rights, and freedom of action, than that stemming from a compulsory licence (or government use). The former only weighs upon the choice between exporting and producing in situ, leaving all other faculties of the right holder fully intact - including the choice between producing directly or through a local licensee of her/his trust and appointment. In fact, quite unlike the local working requirement, the imposition of a compulsory licence (or government use) 'reduces' the patentee's position to little more than that of a simple rentier.

In other words, in more exists less. If the system of TRIPs specifically allows such a heavy restriction/reduction - in terms of compulsory transfer to a third party - of the exercise of such basic patentee's rights as those of producing, distributing, pricing - and this, albeit in exceptional cases, even without requiring a previous attempt to negotiate a contractual licence with the patentee (article 31(b)) - and if all this is allowed to Members, the provision of a local working requirement, as 'a limited exception to the exclusive rights' of the patentee (article 30), might well be equally - recte: even less controversially (and thus more broadly: see below) - introduced? And introduced, as hinted above, in the framework of Members' general faculty to 'adopt measures necessary ... to promote the public interest in sectors of vital importance to their ... technological development', as per article 7 (emphasis added) - thus, for sure but, for example, regarding advanced pharmaceutical processes and products, energy saving and pro-environmental refining methods, cost-saving and safety-enhancing construction techniques, etc., in further support of my argument, I submit that - as concerns the effective technological 'spillover' effect - being subject to a local working requirement instead of a compulsory licence would probably encourage the patentee to transfer and 'keep feeding' her/his local plant, or her/his local licensee more significantly, in quality terms as well as in quantity of know-how, than one would reasonably expect should the same patentee by contrast 'surrender' her/his patent to an unrelated, much less 'controllable' (even vis-à-vis re-export to affluent markets!) third party, chosen and imposed by a foreign government. Moreover, the basic costs of working the patent would accrue to the patentee and her/his licensees, not to the local governments or government-related local firms. And here, may I finally add that even the patentee itself, in order to reduce, partially at least, the costs associated with direct working, might well be encouraged to appoint one or more local licensees of her/his trust. Thus, at the end of the day, the overall benefits associated with working the patent by a local licensee might be achieved more efficiently - and at lower costs for the 
DC in question - than by straight recourse to compulsory licences or 'government use'.

The recourse to an industrial LWR should be a fortiori admissible, if not actually a must, when the patent granted and enforced in a developing country utilizes biodiversity preserved and cultivated thanks to local traditional knowledge. It is well known that in such cases the country and local communities providing the biodiversity are usually compensated financially but not - repeat: usually - also by any significant 'association' in the exploitation of the R\&D based on the germplasm they have nurtured and provided. As recalled elsewhere, ${ }^{94}$ we should interpret the TRIPs Agreement (articles 7 and 8 in particular) in conjunction with the 1993 Rio Convention on biodiversity - which calls for an 'equitable sharing' of the benefits (of all kind) stemming from exploitation of biodiversity (article 15.7). Now, such 'mutually supportive 'interpretation (to borrow the wording of the European Commission's Communication as of 3 April 2000 'on the Relationship between the Convention on Biological Diversity and the TRIPs Agreement') would allow ${ }^{95}$ developing countries that provide biodiversity to require the local working of the patent.

Needless to say, given its specific rationale, this solution should apply in favour of all biodiversity-providing DCs - not only LDCs.

\section{The Economic Roots of the Protectionist Trends}

Underlying the historical roots of such trends is first and foremost the industrialized world's quest for new sources of competitive advantage in global markets as it gradually loses its pre-eminence in mature sectors hence, the increasing attention on innovative technologies and the protection of their exclusive exploitation as a means of maximizing (in the short term) the return on investments. In its turn, this rationale provoking déjà $v u$ in historical cycles of industrial revolutions - stems from some objective aspects of the industrial and financial context of technological innovation.

94 G. Ghidini, 'Equitable Sharing of Benefits from Biodiversity-based Innovation: Some Reflections under the Shadow of a Neem Tree', in J. H. Reichman and K. Maskus (eds), International Public Goods and Transfer of Technology under a Globalized Intellectual Property Regime, Cambridge University Press, 2005, 695.

95 A caveat: such 'mutually supportive interpretation' requires that both TRIPs and the CBD have been signed by the two countries concerned, that is, the one that provides and the one that utilizes the germplasm. 
Amongst such (well-known) factors we can briefly consider are:

(a) The growing extension of competitive conflicts based on technological innovation to ever larger markets, typically on an international scale;

(b) The ease of immediate and perfect duplication of new technologies, such as those related to information and communications, like computer programs (due to their 'bearing the know-how on their surface', to borrow J. H. Reichman's words) and bioengineering (due to the typical self-reproducibility of biogenetic material), an ease that annuls the lead time of innovators and thereby facilitates free riding, hence jeopardizing the recoupment of first-comers' investments;

(c) The increase, exponential in some sectors, of research and development, distribution, and advertising costs (more so, often, than production costs in the strict sense);

(d) The chronic insufficiency, as a result of the widespread implementation of cost-cutting policies, of government subsidies for scientific research, that is, the raw material for applied (industrial) research. The business community is increasingly being called upon to cover the costs of scientific research that were traditionally borne by universities and public institutions;

(e) The need, arising from the factors illustrated above, to attract ever greater amounts of venture capital. Typically, this need is met in financial markets featuring increasingly intense competition in offerings making equity investments more attractive. In turn, such financial competition drives corporate policies aimed at maximizing shareholder value in the short term, hence conflicting with the traditional industrial logic aimed at constant, long-term development of economic activities. Now, this financial short-term bulimia leads to supporting stronger forms of protection of IPRs as 'valuegenerating' instruments, whether on a commercial level (licences, merchandising, etc.) or a directly financial one (think, for example, of IPR securitization). ${ }^{96}$

96 Of course, not all financial evaluation of IP deserves suspicion. For instance, I support the possibility of registering IPRs in the balance sheet at a fair value, possibly prudently higher, according to circumstances (e.g. a relevant portfolio of highly profitable long-term licences), than the historic cost of the acquisition or the material creation of the intangibles. 


\section{The Emergence, and the Economic Roots, of Trends More Open to Competition Dynamics and Access to Information: A Diverging Overall Evolution of Patent and Copyright Regimes?}

Commencing from roughly forty years ago (a short period compared to the more than the two-century-long history of modern IP law), a slew of jurists and economists, whose number and quality are on the rise, arrived on the scene claiming that dominant interpretative trends were substantially shifting (both in general terms and in relation to specific industrial sectors) the centre of IP law further towards monopoly rather than towards competition, so much so as to lead to what Jerome Reichman described as 'a discredited intellectual property system [that] risks collapsing under its own overprotectionist weight' 97 The risk arises precisely from the danger that intellectual property rights be transformed from a tool for the promotion of innovation and competition, into a protectionist barrier in favour of dominant enterprises: that is to say, into a factor that restricts supply and slows down the dynamic processes that generate innovation, while also reducing consumers' alternatives of choice.

This danger, it was also noted, is much more acute vis-à-vis the contemporary general tendency of markets to take on an oligopolistic structure. This tendency threatens all market players: small competitors, both current and potential, who are increasingly deprived of opportunities for competition; consumers, whose range of choice is increasingly limited by sparse offerings marketed at exorbitant prices. And even, in the long term, the dominant firms themselves, encouraged to go on reaping the fruit of their guaranteed earnings, might well be tempted to slow down the pace of further investments in innovation.

The criticism - of varying degrees of intensity - of the 'protectionist drift' naturally leads to the assertion that there is a need to strike a balance (in primis on the plane of interpretation, and otherwise of reform) between 'right' and 'access' in a way that avoids favouring IPRs holders at the expense of collective interests of constructional rank. This balancing act requires that the scope of the IPRs' exclusionary power be strictly commensurate - 'proportioned' - to the satisfaction of their 'essential' anti-free riding function, as highlighted above. A 'reductionist' reading of such power, it was held, can indeed contribute to avoiding the risk evoked by Reichman. Just as slimming the body makes it more

97 J. H. Reichman, 'Beyond the Historical Lines of Demarcation: Competition Law, Intellectual Property Rights and International Trade after the GATT's Uruguay Round', 20 Brook. J. of Int'l Law, 1993, 119. 
healthy and agile, so a loss of IPRs' monopolistic weight can restore the same to their historical functional role to 'promote the progress of science and the useful arts' (article 1.8.8 US Constitution) - and, as concerns trademarks, to ensure market transparency.

However, the protectionist tendencies came under criticism well beyond the band of brothers made up of scholars and judges swimming against the tide (let alone social activists like 'no copyright' or 'copyleft' groups).

An ever-growing number of highly qualified industrial and financial circles, directly or indirectly involved in $\mathrm{R} \& \mathrm{D}$, are advocating, and practising, different business models no longer premised on an acrossthe-board 'exclusionary' view of intellectual property rights.

Even before the digital revolution, more and more industries and R\&D centres came to adopt, on a voluntary (contractual) basis, cooperative models of production and distribution, involving forms of exploitation of patent or copyright protected innovations. Models are thus created whereby new technologies are made-and-shared (through patent pools and/or cross-licences) within the context of collaborative production systems, open within a predetermined group of firms that cooperate with one another in $R \& D$, reciprocally sharing results by co-patenting and/or cross-licensing, 98 while remaining competitors on the market substantially in the 'last mile' of the industrial and commercial process refinement, design, marketing; phases left to the single competitor's own strategy.

The success of these collaborative/'sharing' business models rests on the perception of the superior cost efficiency and overall productivity of R\&D efforts - spurred by 'specialized standardization' - and of using reciprocally compatible components and products for both horizontal and vertical product lines, as well as reciprocally sharing (through patent pools and/or cross-licenses) the specific know-how developed by single firms.

At times, the adoption of models of exploitation of intellectual property rights based on sharing occurred, as it still occurs, in 'promiscuity' with the traditional ('closed') models. In particular, the open source licence model, initially conceived to favour a somewhat restrictive

98 G. Ghidini and A. Stazi, 'Coopetition: The Role of IPRs', in D. Beldiman (ed.), Innovation, Competition and Collaboration, Edward Elgar, 2015, 15. In a broader perspective of 'user innovation', see E. von Hippel, from the seminal 'Lead Users: A Source of Novel Product Concepts', in Management Science, 1986, 791, later developed in The Sources of Innovation, Oxford University Press, 1988, up to the more recent Democratizing Innovation, MIT Press, 2005. 
community of amateur programmers, has given life to a veritable industrial option on which giants like Microsoft and IBM embarked, at least partially, no longer rejecting across-the-board access by third parties to portions of their IPR-protected technologies. This is also increasingly the case in other sectors of advanced innovation: inter alia, the bio- and gene-tech $\mathrm{R} \& \mathrm{D}$, where prominent research centres frequently opt for the disclosure of genetic information in order to avoid future private appropriations thereof through its inclusion in broad patent claims.

The emergence of open ('paying') access models as mandatory originally occurred within the patent regime, through the (exceptional) provisions of compulsory licenses (a) for protracted inertia in implementing the patented innovation, and (b) on derivative patented innovation with a high technical and economic profile (the normative model also supported by TRIPs, article 31.1): a provision especially relevant for enhancing dynamic competition.

A powerful boost to the extension of the paying access scheme as trend-setting legal model in the contemporary industrial scenario, as shaped by the digital revolution, was firstly provided, as an expression of a general policy, by the legal developments in the ICT sector - one that lives and feeds on interconnections. Here, the original exhortation, issued by EU institutions in promoting a policy of liberalization of the telecommunication sector, to make communication standards as open as possible under 'fair and non-discriminatory' terms, led to the experience of 'voluntary' licensing of communication standards under the bylaws of the Standard Setting Organizations (SSOs) (below, Chapter 5, section I).

Then, a further 'interference' of antitrust in the exercise of IPRs - a distinct interference (originally emphasizing its own 'exceptional' character), ${ }^{99}$ but basically relying on the same substantive rationale - evolved from the original perspective of sheer contrast with the competition rules of the EC Treaty to the jurisprudential extension, even at ECJ level, of the doctrine of 'essential facilities' to immaterial assets, hence of a duty to grant access ('fairly' paying access) to competitors even outside any unlawful exercise of the IPRs. This was to occur vis-à-vis the 'indispensability' of the protected intangibles to achieve (or to achieve in economically efficient, i.e. 'competition-compatible', conditions) a certain industrial goal/result; in other words, to avoid that the exclusionary exercise of the IP entitlement (in itself a quite legitimate, nay: statutory

99 On this see below, Chapter $5, \S 4$, also as concerns the debate on the application of the Essential Facilities (EF) doctrine to foreclosures on the primary, horizontal market, or just on the secondary, downstream market. 
exercise) might lead to significant foreclosure of competition on the market(s) concerned, whereas the granting of a right to access would enhance dynamic competition by allowing 'more hands' to develop and 'work on' advanced innovation. (On this, see broadly in Chapter 5, below.)

In sum, the new 'mode of production' typical of the digital age is heading to set the manifest destiny ${ }^{100}$ of the industrial development - and this, particularly in the prospective of Internet of Things. ${ }^{101}$

A similar evolutionary trend of business models, as adopted on a voluntary (contractual) basis, occurred also in the domain (at large) of copyright. In particular, as concerns the production and online diffusion of contents in digital format - news, materials for research, entertainment, etc. - the industrial necessity emerged of filling up the new 'information highways' made available by the increased transmission capacity brought about by the e-technologies; the necessity, in other words, to avoid having 'more high-speed networks than they know what to do with'. 102

In turn, this necessity fine-tuned with the economic opportunities disclosed by business models and distribution policies that enable access to and exchange of content free of charge or at a low cost while still making a lot of money. These different policies are mainly based on other sources of income such as low-cost subscriptions, online advertising and offers of additional services (both 'linked' to the content transmitted),

100 Needless to say, this is a global trend that extends beyond the boundaries of the most industrialized countries (above, § 14) to a growing number of developing countries, in particular the 'technologically proficient' ones ( $\mathrm{S}$. Basheer, supra, fn 79 and accompanying text), BRICs first and foremost.

101 A caveat against indiscriminate, 'totalizing' expectations. As the emergence of open access legal models ('paying' models, however, when oriented to commercial exploitation) depends on their objective functionality to the new, trend-setting 'mode of production' brought in by the digital revolution, so the traditional patterns will survive, and even thrive, vis-à-vis, first of all, the persistence of some of the specific objective factors just highlighted above. Thus, for example, vis-à-vis certain industrial sectors' peculiar characteristics (e.g. highly capital-intensive industries intensely competing within super-oligopolistic markets: such as 'big pharma'); and also vis-à-vis the business environment of smaller enterprises, to the extent that it will remain diffusely imbued with a historical culture - also shaped by the lack of robust fiscal and financial sticks-and-carrots to engage in networking in R\&D - of 'individualism' and reluctance to engage in inter-enterprise cooperation.

102 'A World of Connections: Special Report on Telecoms, The Economist, 28 April-4 May 2007. 
sponsorships, live performances, including an 'invisible' price increase of the hardware (for example, mobile phones) used for downloading content. Thus, the user pays just a little or indeed nothing at all (in return, agreeing to be the recipient/'contact' of advertising, as well as the provider of commercially exploitable personal data. Hence the firm earns from sources other than the straight 'price', thereby also avoiding the costs (monetary and image-wise) of having to pursue users and/or servers through the courts. ${ }^{103}$

Thus, with regard to both the 'productive'/creative profile (development of new contents) and that of the online publishers/end users relationship, the traditional exclusionary copyright model has appeared to many, even from within business circles (not all, perhaps not even the majority: see later below) to be a straitjacket, a shirt of Nessus, imposed on the new promising productive and distributive perspectives. The Economist itself - hardly a subversive voice - already in 2003 had called for a 'radical rethink' of the reductionist sense of copyright, and this with the very purpose 'to foster creativity in the digital age'.

However, as concerns the vast, 'classic', domain of non-utilitarian contents (cultural and informational ones, of merely intellectual/aesthetic fruition), the copyright statutory paradigm has so far basically held fast to the hegemony of the traditional exclusionary model.

Suffice it here to remember that the copyright paradigm still does not host a regime of compulsory licences (with the limited exceptions discretionarily allowed by the Berne Convention under articles II-bis (2) and 13.1: see below). On the contrary, even in the digital era (and under ad hoc 'reforms'), it has introduced and maintained new 'filters' both ex ante (enforcement of anti-access technological protection measures, TPMs) and ex post - as a three-step test, at judicial level, which reduces the scope of third parties' actual chances to enjoy even exceptional instances of open (at time paying) access based on eminently nonlucrative grounds of public interest. Not to mention the historical trend to progressively extend the duration of the exclusive right, and vice versa to

103 A policy of obstacles or even legal persecution of individual users can be a wasted effort not only because of the legal costs, but above all because of the negative effects on social consensus (that is, on image and hence customers) that firms need to retain, especially in sectors that involve great masses of consumers and users, in order to grow and face the competition. Leading IT and communications companies have progressively abandoned those technological protection measures (TPMs) capable of hindering access to and the exchange of digital data, information, text, images, music, etc. in communication networks. 
progressively restrict the scope of implementation of 'derivative' creativity, can be seen, as in the revealing case of the regime of translation, the essential instrument of the circulation of culture and information at the international level (see broadly, Chapter 3).

All this concerns the statutory regime of copyrighted works of a non-utilitarian nature; whereas, as regards certain copyrightable technological products, software in particular, the all-exclusionary paradigm has been 'interfered' with by competition law.

More precisely, and comprehensively (since the diverging trend is not limited to patents), in the domain of advanced technologies - in particular the 'essential' (indispensable/standard ranking) ones (see below, Chapter 5) - the general interest sub specie of protection of competition has 'interfered' with the statutory exclusionary right of patent and/or copyright holders, affirming a duty to grant paying for access, at 'fair, reasonable, and non-discriminatory (FRAND)' terms, to 'willing licensees', i.e. (competing) implementers and followers. This has occurred more frequently with patents (the typical protective IPR of technology), but also with copyright, in so far as the latter protects technological works - software in particular - as in the Microsoft saga.

A similar evolution has not occurred, as hinted, in the 'classic' domain of copyright - that of works for purely intellectual/aesthetic fruition, protected as regards the 'expression', not the conceptual content (below, Chapter 3). In such a domain, given the unlimited variability of the expressive form, substantially no competition-related concerns arise, so antitrust has nothing to get its teeth into.

In this domain then, under the overarching (other) general interest in the diffusion of culture and information, several national legislations have statutorily consented (exercising the discretionary faculty allowed them by the Berne Convention: see articles 11-bis (2) and 13.1) that even without the rights holders' authorization (but upon equitable remuneration of the same and the safeguarding of authors' moral rights) copyrighted works may be publicly broadcasted and communicated to the public (article 11-bis (2)) and also registered (article 13.1). ${ }^{104}$ The administration of such systems, including the collection of remunerations (in some countries statutorily determined (a statutory licence), in others, left to private agreements in default of which a public authority would fix the amount (a compulsory licence)), is typically implemented via collecting societies.

104 See G. Davies, 'Copyright and the Public Interest', IIC Studies in Industrial Property and Copyright Law, vol. 14, 1994, at 166. 
The existence of these limited exceptions cannot overcome the fact that the dynamics of creativity - the chain of diffusion of derivative works entirely rest under private control: typically of publishers and other 'final holders' of copyrighted works. Thus, in a prospective incisive reform of the copyright regime (unlike that proposed by the EU Commission in September 2016; below, Chapter 3), wide room should be given for allowing those general interests to 'interfere' with the present exclusionary paradigm. After all, these interests, which project on the democratic physiognomy of modern society, enjoy a superior constitutional rank to that of preserving economic competition in the market. Accordingly, models of compulsory licensing should be introduced (in a broad analogy with the 'essential facilities' doctrine: isn't the original work 'essential' for realizing translations?!) in order to allow, much more widely than the present positive framework does, that the 'subsequent cultural innovation' (i.e. derivative works, such as first of all translations and transformations into different representative expressions - adaptations for children, for example) be given a reasonable green light. ${ }^{105}$ By 'reasonable' I mean both distinguishing between 'access for knowledge' (non-commercial) and 'access for exploitation': the latter to be granted on paying (FRAND) terms. And I also mean preserving the right of individual authors to defend their moral rights - for example to oppose the granting of licences for translation or adaptation to a publisher 'specializing' in pornography. (For more on all this, see below, Chapter 3.)

\section{On the Role of IPRs in the 'Open' Models}

The growth of 'open' models, fervent in economic practice even beyond the ICT sector, does not annul the justification for IP entitlement. This is for a number of reasons.

Firstly, for the creation of new technology and/or intellectual works, ownership of a patent or copyright often remains - precisely because of its efficacy erga omnes - a reliable tool for authors interested in guaranteeing their chances of being remunerated in the event that their work is successful even when they entrust circulation thereof to open systems. ${ }^{106}$ See, for example, the ever more frequent case in which the

105 I would include publication in low-cost editions (which does not mean low quality - just think of Penguin), for the cause of the general interest in popular diffusion of cultural works.

106 Needless to say, the fact that some inventors and authors for various personal reasons - humanitarian or self-promotion - give up exclusive rights 
distributor disseminates music, images and words for 'free' and obtains his return on investment from advertising revenues. Here, the entitlement of copyright, with its erga omnes effectiveness, actually constitutes a more reliable guarantee (compared to a merely contractual right, enforceable only against the direct counterparty, the publisher in particular or the provider) to claim the right to remuneration, possibly even in the form of a share of advertising revenues, against all persons (and domains) that comprise the distribution chain - including platform operators - and obtain commercial revenues from that distribution model.

Secondly, when an author or inventor wishes to entrust her creation to a distribution chain that also permits transformation of the work by subsequent users-creators (the scheme underlying the Creative Commons model), is it not perhaps the IPR of the creator (originary licensor) that enables the integrity of the system to be defended against both unfaithful licensees and third parties to whom an unfaithful licensee had transferred the original work and/or its 'derivative' modifications?

Last, but not least, is it not perhaps the entitlement of IPRs that, interacting with the exercise of freedom of contract, favours the recalled historical trend to organize research, production and distribution in all industrial sectors under cooperative patterns - even including competitors ('coopetitors')? And this, as hinted above, is precisely because of both the intrinsic business appeal of a partnership capable of bringing technology with a 'certified' innovative value, and the just evoked erga omnes protection that such ownership entails.

\section{FOR A BALANCED RECONSTRUCTION OF IP REGIME(S): METHODOLOGICAL CRITERIA AND EXAMPLES OF THEIR APPLICATION}

\section{A Dual 'Concentric' Systemic Perspective}

In the ensuing analysis of the various fundamental paradigms of intellectual property (and their 'intersection' with competition law) I will attempt to sound out, as hinted above, the viability, modes and limits of a line of a reconstruction of the dialectic between exclusion and access that underlies the regime of the fundamental paradigms of IP law attempting to (re)balance the legally relevant interests at stake so that the protection

does not change the terms of the issue: the recourse to IP 'instruments' is obviously facultative (see again below Chapter 2, § 21)! 
of IPRs holders may not encroach on other stakeholders' rights and interests, individual and collective, that also share constitutional rank (in the substantive or formal sense).

The methodological criteria, and their corollaries, that will guide such an attempt, converge in a dual concentric 'circle' made up of (A) the body of specific regulatory principles of those fundamental paradigms and (B) the body of the constitutional principles (in a formal or substantive sense) in relation to which IP law must also be interpreted up to the limit of textual obstacles that call for reform to be overcome.

(A) As regards the first 'circle', I refer to the need for a consistent interpretation of the regimes of the various IP paradigms: ${ }^{107}$ one whereby the rules of one paradigm should be read in a manner that does not contradict the rules that, on the same substantive subject matter, another paradigm expresses in relation to a distinct protective function. So, for example, the holder of an expired model registration should not be afforded the protection of a 'de facto (shape) mark' to prolong, potentially without time limits, ${ }^{108}$ the exclusive exploitation thereof (see below, Chapter 4).

(B) The second 'circle' concerns a methodological line of more complex application that prescribes a reading of IP law coherent with the legal principles of constitutional rank referable to the activities involved, and the claims advanced, within the conflicts of interest, between IPRs holders and third parties, sparked by the exercise (and, less frequently, the entitlement) of intellectual property rights. ${ }^{109}$

A cultural approach to IP law analysis (and related reform proposals) aims at construing normative solutions of the substantive conflicts of interest underlying IP-related issues, in a long-term perspective that marries 'holistic' with 'functional/instrumental' - where holistic refers to

107 Principle of consistency, according to the definition given by N. McCormick, 'Coherence in Legal Justification', in A. Peczenik, L. Lindhal, and B. van Roemund (eds), Theory of Legal Science: Proceedings of the Conference on Legal Theory and Philosophy of Science, Springer, 1984, 231-251. See also A. M. Rosenberg, The Nature of Common Law, Harvard University Press, 1991, Ch. 5.

108 On this point, may I refer to my essay 'From Here to Eternity? On the Overlap of Shape Trade Marks with Design Protection', in J. Drexl, M. Hilty, L. Boy, C. Godt, and B. Remiche (eds), Technology and Competition: Contributions in Honour of Hanns Ullrich, Larcier, 2009, 55 et seq.

109 Principle of coherence: N. McCormick (1984), 'Coherence in Legal Justification', cit. fn 107 above. 
the aforesaid need to analyse the IP paradigms in their mutual connections (convergences/divergences) under the imperative of noncontradiction, and functional/instrumental means systemically consistent with the principles of constitutional rank overarching the exercise of IP-related activities. In particular, the principles grant, even on the plane of human rights, the fundamental freedoms of expression - in the active and the passive sense ${ }^{110}$ - and economic initiative - within its limit of respect for pre-eminent collective and individual interests, such as inter alia health, education, privacy, personal dignity, etc.

This line translates, first and foremost, into respect for the principle of numerus clausus, according to which IPRs are strictly defined by law in number and kind. ${ }^{111}$ Said rights grant powers in restraint of competition, and are therefore to be deemed exceptions to the constitutional principle of economic freedom - islands in a sea of freedom. An important corollary of such assertion relates to the interpretation of the so-called 'exceptions' to IPR holders' exclusive power. When, as typically, such exceptions are grounded on a constitutionally ranking general principle of freedom - such as that of research in the 'experimental use' exception provided for in the patent regime - it should be borne in mind that we are dealing with 'exceptions to exceptions' - the principal exception being the patentee's exclusive power itself, while the 'exception' thereto reflects, as said, a general principle of freedom. As such, then, as hinted in fn 69, said 'exception' should not be subject to 'strict interpretation' contrary to the current formalistic (and objectively protectionist) approach. Accordingly, its scope should be extended ('fairly', as in US copyright law) so as to include hypotheses that, although not textually mentioned, reflect the same rationale as expression of the same general principle. Just think, for example, of the extension of the 'exception' allowing the free use of copyrighted works for teaching purposes to the faculty of translation, by or under the teacher's supervision, of foreign texts for subsequent distribution to the students.

Needless to say, acknowledging the principle of the exceptional character of IPRs does not hinder the extension by legislation - by

110 I.e., on the one side, production and spreading of culture and information, and, on the other, diffuse access thereto.

111 Obviously the numerus clausus pertains to the 'types' of intellectual property rights as such, not to their material 'subject-matter', which has sometimes been left undetermined. Just think of the formula adopted by the EPC, article 52, to describe patentable subject matter: 'any inventions, in all fields of technology'. See also USC Title 35: 'any new and useful process, manufacture, or composition of matter, or any new useful improvement thereof'. 
legislation, not interpretation - of the nucleus of intellectual property rights beyond those currently protected. Historically, indeed, these rights have been progressively extended: one need only consider, for example, the 'new' exclusive rights introduced on the layout design for integrated circuits and industrial design.

Along the same method lines the interpreter should privilege, whenever reasonably possible, a reading of the IPRs regime coherent with the respect of the other principles of constitutional rank; for example, one that - while safeguarding IPRs' essential anti-freeriding function defends rather than erodes the economic freedom of third parties, as well as the market's competitive fabric, or upholds rather than prejudices the freedom of information (below, Chapter 3, $\$ 2$ ).

To take just one example: in identifying the scope/extent of a patent, the interpreter must limit it to the particular technical field and technical solution that the inventor has specifically claimed in the patent application. ${ }^{112}$ If the notion of infringement were to be construed so as to extend the scope of exclusive rights beyond the strict quid inventum, the development of subsequent innovation would be discouraged. Third parties (competitors of the patent holder) penalized by such an interpretation would in fact have no incentive to invest in 'too' risky attempts at improving and/or modifying previously patented techniques. And the patent holder himself, benefiting from such an over-protectionist interpretation, would be tempted to make 'rent' out of her acquired competitive advantage, rather than rolling up her sleeves to further search and invest in innovation.

\section{The Problem of Balancing Different Interests All of Constitutional Rank}

Observance of the two canons of construction just now presented is complicated by the possibility that all the interests involved enjoy a constitutional status: those of IPRs holders, those of third parties to gain

112 See, in particular, article 69(1) EPC, according to which 'the extent of the protection ... shall be determined by the claims'; whereas 'the description and drawings shall be used to interpret the claims' the scope of a patent is to be determined by the wording of the claim. Moreover, Rules 42 and 43 of the Implementing Regulations of the European Patent Convention require the inventor to indicate in detail all of the elements of the patent. As regards biotechnology, article 5(3) of Directive 98/44/EC demands that the industrial application of a sequence or a partial sequence of a gene be disclosed in the patent application. 
access, as well as the multifaceted collective interests highlighted above. Regarding the rights of the entrepreneurial holders of IPRs, it is undeniable that they are of constitutional rank as functional expression of freedom of enterprise (above, $\S 1$ ). Moreover, as concerns inventors and authors, their 'moral and material interests' ${ }^{113}$ are qualified as 'universal', i.e. human rights. ${ }^{114}$

So how does one resolve, employing a systemically correct approach, the conflict between IPR holders and third parties' rights of access, underpinned by the constitutional supporting freedom of expression and information, freedom of competition, the protection of health, etc.?

To that end two further interpretative tools come into play, in logical sequence, the first of which concerns the qualification of the interests at stake, the second the balancing thereof. I am referring to the principle of hierarchy between various rights and interests all of constitutional rank and the principle of proportionality in balancing conflicting recognized rights.

Not all rights of constitutional rank were born equal. Even in the European Convention on Human Rights some rights outrank others. ${ }^{115}$

113 See article 27(2) of the UN Universal Declaration of Human Rights, approved by the General Assembly on 10 December 1948, which provides as follows: 'Everyone has the right to the protection of the moral and material interests resulting from any scientific, literary or artistic production of which he is the author'. That provision has elevated intellectual property rights to the level of human rights. On this point see P. Torremans, Copyright and Human Rights, Kluwer Law, 2004, 5-6. In a European Context, see article 17(2) of the Charter of Fundamental Rights of the European Union (2000/C 364/01), in OFEU C $364 / 3$ of 18 December 2000, which requires Member States to protect intellectual property.

114 According to a view of P. K. Yu that I fully share (see above, fn 32) this status does not apply to intellectual property rights owned by firms. This does not detract from the fact that even the firms' right to exploit IPRs enjoys a constitutional rank - precisely under the profile of the exercise of the freedom of economic initiative - a rank, however, hierarchically subordinated in respect of 'higher' constitutional values directly reflecting general interests such as encompassed in the concept of 'social utility' (amongst which, please note, is the preservation of a workably competitive market framework) as well as by those directed to the preservation of human health - and, may I emphasize, to the preservation of a workably competitive market fabric: a general interest distinguished from the individual one of single competitors.

115 For example, private property can be limited in order to safeguard a public interest: that hierarchy (implicit in several Constitutions, including in the Italian one) can be found in the Protocol of 20 March 1952 to the European Convention for the Protection of Human Rights and Fundamental Freedoms - 
The legal system (to be more precise, the various legal systems of democratic countries, which may feature several differences, but tend to converge in the basic principles, especially if democratic ones) makes the exercise of some rights subject to more limitations than others. A typical case, drawn from the Italian Constitution, but implicitly of general value (at least in the European framework), is that the freedom of economic enterprise may be exercised within limits that cannot be applied to the freedom of expression. Thus, for example, advertising messages, in as much as they stem from the promotional activities of a firm, can be censored if misleading or even made subject to prior authorization (think for example of pharmaceutical advertising) whereas such conditions and limits are inconceivable for messages and communication diffused within the political debate. ${ }^{116}$

I wish to stress that in reconstructing the constitutional hierarchy, the positive jurist must not adopt this or that ethical-philosophical (or justice) theory that appeals to her, as a guiding light for the interpretation and application of the law. Legislators and judges, whose task is not - unlike that of philosophers - to elaborate personal Weltanschaaungen, but to regulate and adjudicate 'right and wrong' as regards the behaviour of

see in particular the second paragraph of article 1. Other provisions make it clear that certain rights are not susceptible to any limitation: see in particular article 3 of Protocol No. 6 of 28 April 1983 to the said Convention providing that there can be no derogations to the abolition of the death penalty.

116 See the European Court of Human Rights (ECtHR), MarktinternVerlag GmbH and Klaus Beerman v. Germany, 20 November 1989; ECtHR, Lindner v. Germany, 9 March 1999; ECtHR, Colman, 28 June 1993. In particular, on this specific case see European Commission on Human Rights' Report, October 1992. On the general principle, see also Italian Constitutional Court judgment no. 68 of 12 July 1965, in Giur. Cost., 1965, 838.

Among scholars see M. Birnhack, Copyrighting Speech: A Trans-Atlantic View, in P. Torremans (ed.), Copyright and Human Rights, Kluwer Law, 2004, 42.

What is important is the objective purpose of the communication and not the means/media employed. If a firm participates in public debate through paid advertising (e.g. to criticize a certain industrial policy), its message is fully protected under the principle of freedom of expression. Not so when it promotes products/services for sale, in which case its communication is protected under the principle of freedom of enterprise - hence a freedom subject to limits that are 'non admissible' vis-à-vis freedom of expression - just think of the prohibition of misleading statements in commercial advertising - a prohibition unthinkable in relation to political speech. 
citizens, must comply with the positive constitutional rules that both legislators and the courts must respect in the exercise of their respective functions.

The concept of constitutional hierarchy embraces the hypothesis of convergence of the different interests of constitutional rank: in particular those directly referable to individuals and those of collective scope and 'nature'.

In particular, there are cases in which the conflict between distinct private economic interests can be resolved through a comparative assessment of the effects of the behaviour and/or acceptance of the private claims over safeguarding the collective interests evoked by the conflict itself. While the satisfaction of some interest remains confined to the private sphere, that of others can also entail the attainment of collective interests. In that case it is legitimate, indeed mandatory, to privilege that convergence. ${ }^{117}$

This and other normative confirmation of the hierarchical approach must encourage consistent lines of interpretation in solving the conflicts of interests raised by the exercise of intellectual property rights (lines to be implemented then according to the criterion of proportionality: see below $\$ 20$ et seq.) so as not to sacrifice the essential function of the intellectual property right whose typical exclusionary power is transformed into a right to remuneration; for example, a conflict between copyright holders and third parties claiming access to protected content on the basis of 'exceptions and limitations' - or, better, 'free uses' (Berne Convention, article 10: see below, Chapter 3, section IV) - grounded on reasons of public debate, teaching, research, etc. Both individual positions are legally protected: but the position seeking knowledge-aimed access (as distinguished from that 'for exploitation', business-aimed) is of higher constitutional rank because it also satisfies the public interest in the dissemination of culture and information.

\section{The Constitutional Hierarchy of Protected Interests}

As mentioned above, the second tool to be used in the hermeneutic sequence, serves a precisely applicative role in balancing the conflicting interests: it is the principle of proportionality. In the sense understood

117 On this assumption may I also refer to my own 'Exclusion and Access in Copyright Law: The Unbalanced Features of the InfoSoc Directive', in G. Dinwoodie (ed.), Methods and Perspectives in Intellectual Property, ATRIP IP Series, Edward Elgar, 2013, 307. 
here, it consists of two requirements:118 (a) that any reduction, or in any event transformation (especially from an exclusionary right to one that entails remuneration), in the enjoyment of a constitutionally protected individual right must be based on grounds of general interest provided for by law; and (b) that where such occurs, legislators and judges must balance the interests at stake in such a way as not to sacrifice the essential function of the 'lesser' right. ${ }^{119}$

A good example, from patent law, concerns follow-on (derivative) innovation (see further, Chapter 2, § 23). Here, even at international level (see TRIPs, article 31.1), the legal framework endorses the faculty of national legislators to transform '(intellectual) property into liability', i.e. the excluding power of the holder of the original patent (A) into a right of remuneration by the creator of a derivative invention (B) whose improving contribution exhibits considerable technological or economic features, and who requests to share in the exploitation of the original patented invention - this, even in the absence of any dominant position on the part of the former.

Thus, the collective interest in promoting high-profile innovation while at the same time enabling the community as a whole to benefit from more advanced products/proceedings (for example, drugs whose dangerous side effects have been eliminated by the dependent invention) is valued more highly than the exclusionary right that the holder could in principle exercise until the expiry of its monopoly.

Valued more highly, and applied 'proportionately' - and this not only because the creator of the originary invention is granted the right to a fair compensation, but because she/he is also granted in his turn, the right to

118 Ex multis see N. Reich, 'How Proportionate is the Proportionality Principle? Some Critical Remarks on the Use and Methodology of the Proportionality Principle in the Internal Market Case Law of the ECJ', in The European Court of Justice, Intersentia, 25 October 2011, 83.

119 By the way, this dual requirement also informs solutions to conflicts of interest in the field of tangible goods. For example, if a public authority needs a portion of private land on which to construct an electricity pylon, the authority should (a) choose, where possible, a portion of land that is not near a private dwelling or is furthest away from it and (b) in any case pay the owner compensation depending on the actual value of the land. Again, in the case of compulsory servitudes, the inconvenience and possible damage suffered by an owner who has to grant a right of way must be compensated. Not only that, but also reciprocally, in the sense that the manner in which the right of way works must be such as to satisfy the need (essential interest) of the owner of the fund beneficiary of the servitude while at the same time causing the least amount of harm possible to the servant tenement. 
request a cross-licence (also on a fairly paid basis) ${ }^{120}$ in respect of the improvement made by the dependent inventor. This guarantees the first patentee that the value of his patent investment will not be destroyed by the entry of the more advanced technology tout court in the market. Both inventors, thus, will bring into the market the overall more advanced technology $(\mathrm{B}+\mathrm{A}=\mathrm{A}+\mathrm{B})$, with obvious additional benefits for consumers. I will return to this mechanism in $\S 23$ of Chapter 2.

\section{Some Examples of the Application of the Method Guidelines Adopted}

Let us now briefly consider ${ }^{121}$ some examples of the application of the above-mentioned principles of interpretation and methodological lines to typical conflicts of interest between holders of those rights and third parties demanding access for knowledge or exploitation purposes.

\section{(A) Conflicts between holders and third parties demanding access 'for exploitation'}

In relation to these types of conflict (which do not take into account straight free riders, against whom the exclusionary power always remains intact), we have to distinguish between two different situations: (i) that in which the IP entitlement is either illegitimately or however invalidly acquired, ${ }^{122}$ or is 'misused' in order to achieve unlawful objectives, like restraints or other distortions of the freedom of trade; and (ii) that in which a legitimately entitled IPR holder simply exercises her statutory right to exclude unauthorized third parties.

120 Presumably, indeed, in the reciprocal offsetting of the royalties, the owner of the original invention may often retain a differential economic advantage. And will retain, thanks to reciprocity of licences, also a commercial lead time, at least for a certain amount of time: this is precisely because he will be able to incorporate the derivative improvement in his original inventive 'package', without being blown away by the new improved technology. Thanks to this, his market position will continue to benefit from the goodwill accumulated before the appearance of the dependent inventor (more below, Chapter 2).

121 See further, the ensuing single chapters dedicated to each fundamental IP paradigm (patent, copyright, trademark).

122 Think for example, respectively, of a patent or a Supplementary Protection Certificate (SPC) obtained thanks to misleading information provided to a Patent Office, as in Astrazeneca; or one that lacks novelty or 'inventive character' (below, Chapters 2 and 5). 
In situations of the first type, third parties can obtain access to the intangible at stake either upon across-the-board 'removal' of the entitlement (as from a declaration of invalidity thereof), or by an assessment of its illegitimate exercise (as from a declaration of its contrast with competition law). In both cases, of course, their access is 'free': a right to a compensation of the illegitimate IPR holder or the author of an 'abusive' conduct is of course simply inconceivable - in addition, the wrongful behaviour is subject to sanctions and penalties.

In contrast, in situations of the second type, third party 'willing licensees' can obtain a right to access the protected intangible only in specific (a term I prefer to 'exceptional') circumstances. Some are statutory, as in the cases where compulsory licences provide for either the case of a patent holder's protracted inertia in bringing to the market the fruits of the invention, or in the just hinted at case of the right to a licence granted to the author of a high-tech-dependent invention.

In another set of cases, third parties can obtain a right of access - cases so far the product of a judiciary, already dominant line that will be extensively dealt with in Chapter 5. Suffice it now to emphasize that this line, rooted in the antitrust 'interference/intersection' with IP law, aims at 'correcting' market foreclosures stemming from objective circumstances whereby the IPR entitlement (typically patent or copyright) translates into a position of market power stemming from the absence of efficient substitutes of the protected technology, as typically when such technology has been 'elected' or however judicially assessed as 'standard' or 'essential to a standard'. In these cases, contrary to those described above under (i), the IPR holder cannot be reproached, being legitimately entitled to an innovation so advanced that it deserves to be recognized as 'non substitutable'. Thus, the antitrust intervention has no adjudicatory character here (as it does not assess and sanction any tortious conduct), but only, as said, that of an objective correction - intrinsically regulatory in nature (below, Chapter 5, section I) - of an objective situation of market foreclosure. ${ }^{123}$ Consequently, in these cases, the IPR holder will be bound to grant access (but) upon FRAND terms, where 'fair' also means 'fair' for the IPR holder itself (involving the recoup of investments and adequate compensation for the work and the achievement, etc.). ${ }^{124}$

123 Just think, for example, of the Microsoft saga and the settlement reached between the Federal Trade Commission and Google (below, Chapter 5).

124 On the criteria for calculating FRAND royalties in order to balance the holder's legitimate interests with those of licensees to effectively access the market see below, Chapter 5, § 7 . 
At this point it must be briefly anticipated (more below, Chapter 5) that the shift, whether as a result of rules within the paradigm itself (as in the case of an important technical advance) or of antitrust 'interference' (see Chapter 5) from property to liability (except of course vs. straight free riders), does not per se entail frustration of the essential interest protected by the intellectual property right. The granting, forcible as it may be, of licences to (paying) third parties does not per se translate into a reduction of the holder's earning potential, whether from direct exploitation or through the licensees chosen by the holder itself. As a double check, developers of top notch technologies 'rush' to conquer the status as 'standard', which, yes, will oblige them to grant FRAND licences - but also ensure them the status of guaranteed beneficiaries of an undetermined flow of royalties. Moreover, their chances of earning more are increased if the licensees have greater commercial abilities than the 'inventor'. Finally, the obligation to receive adequate (FRAND) royalties could mean that the IPR holder retains an additional advantage over the non-voluntary licensees and immanent competitors, in that the burden of the fees constitutes an increase in rivals' costs. ${ }^{125}$

\section{(B) Conflicts between holders and third parties demanding access 'for knowledge', i.e. without exploitation (and in any case not on an industrial scale)}

In this regard both patent and copyright law provides for specific exemptions from subjection to a holder's exclusionary power and, in certain cases, also from any obligation to compensate the IPR holder, in favour of third party bearers of interests of constitutional rank like freedom of research, teaching, public debate, etc. Those exemptions are assured to the extent that the exercise of the right of access remains knowledge-related and is not transformed into access to enable commercial exploitation of a given intangible: whereas access for commercial exploitation can well be subject to paying the IPR holder an appropriate remuneration (the two hypotheses reflect the difference in copyright law between exception and limitation: see below Chapter 3).

On the basis of the same economic rationale, some types of exploitation, though lucrative but not significant in competitive terms for the essential interests of the holders (above $\$ 5$ ), are likewise permitted - as in the recalled case of extemporaneous preparations of medicines for individuals by the pharmacist on the basis of a patented formula. In such

125 On both points see W. Baumol, The Free-Market Innovation Machine: Analyzing the Growth Miracle of Capitalism, Princeton University Press, 2002. 
case, the negligible economic significance of the claimed access, coped with the collective interest of health care, justifies that access be allowed without duty of compensation (Chapters 2 and 3, below, §9).

Copyright law provides for two (seeming) derogations from the general principles just evoked; namely, as concerns: (a) the direct online dissemination in digital form of works protected by copyright or neighbouring rights; and (b) the distribution, again in digital form, of protected works on 'readable' media (DCD, DVD) that can be accessed through special purpose media players.

In such cases, then, the legal system requests a compensation duty even in instances of private access to the work without any commercial purposes being involved. Later on (Chapter 3) we shall discuss the various methods envisaged for assuring that compensation is made (e.g. encryption of the works disseminated online or a surcharge on the price of playback equipment). What is important to understand at this stage is that the obligation to pay, even for private non-commercial access, does not constitute a real contradiction of the often recalled general rationale of exclusive rights as defence against free riding of 'considerable economic significance' (above, I labelled such provisions as 'seeming' derogations). It is indeed easy to see that the economic negligibility of single, individual private accesses and uses can be exponentially projected on a huge scale thanks to the 'on time' speed, the ease and the perfection of online transmission and retransmission that the digital format permits compared to the analogue format. Thus, in short, millions of individual accesses and recordings, innocuous by themselves, if done free of charge could give rise to the same typical final effect of piracy organized on a large scale, i.e. thwarting the expectations of the holders in recovering their investment and making a profit.

\section{Conclusion}

The next chapters will be dedicated to a reconstruction of the basic features of each IP fundamental paradigm (patent, copyright, trademark), that will be carried on along the holistic and functional lines evoked above - where holistic refers to the aforesaid need to analyse the IP paradigms in their mutual connections (convergences/divergences) under the imperative of non-contradiction, and functional/instrumental means that the resolution of the substantial conflicts of interest underlying the exercise of IPRs (thus, of the assessment of 'who gains who loses') is 
realized in systemic coherence, with the principles of constitutional rank overarching the exercise of IP-related activities. ${ }^{126}$

This reconstruction will proceed avoiding any forced homologation of the single paradigms - while however keeping track of the reciprocal convergences/divergences (in consideration of their own peculiar combination/balance of 'right' and 'access') - including in the hinted different degree and intensity of evolution towards open models of access to the protected immaterial assets. The final chapter will be dedicated to the 'interference' of competition law(s) on the IPRs' regime.

The analysis and the ensuing interpretative proposals (some reform proposals, too) will basically refer not to national legislations as such but rather to principles and lines of argument that are substantially common to the ongoing IP debates in industrially advanced countries, while also projecting onto the relations between the latter and the developing countries. There is a high degree of cultural homogeneity, almost a lingua franca, which does not at all contradict the existence and persistence of differences, at times deep (above, $§ 18$ ), between normative and interpretative approaches within the various legal systems, as well as between different systems (just think of the persisting differences between Europe and the United States, concerning, for example non-voluntary licences).

These divergences and convergences ultimately testify to how deeply IP law is moulded in connection with history. As such, it reflects at the same time (a seeming contradiction) both different patterns and stages of industrial development, legal tradition, culture, etc., and an increasing homogeneity in the prospects for technological advancement and closer transnational economic integration. ${ }^{127}$

In concrete substantive terms, the proposed reconstruction will aim at assessing the present and potential capacity of the intellectual property system to work and evolve so as to ensure that the legitimate interests of IPR holders receive a protection consistent with the satisfaction of the ultimate goals set by the overall system of IP law - including of course, its functional tenets of constitutional rank: first and foremost the promotion of 'science and the useful arts', and the pursuit of effective market transparency through truthful reliable information (as distinguished from mere 'suggestion').

\footnotetext{
126 See above, $\S 18$.

127 Ex multis see A. Peukert, 'Intellectual Property: The Global Spread of a Legal Concept', in Kritika: Essays on Intellectual Property, vol. I, Edward Elgar, 2015, 114.
} 
Please do not get me wrong here. I do not at all envisage a reconstruction aiming at functionalizing the firms' own activity in exercising their IPRs. IPRs' protected assets are instruments of the firm's organization and strategies, and as such their 'use' is essentially determined by the firm's individual 'freedom to do business' (article 16 ECHR). It is the legislator, the judge, the scholar who should keep the helm fast on those tenets (and the basic question 'who gains, who loses'), as the overarching guidelines for their work, and responsibilities, in shaping and interpreting the law - thus safely steering their vessels through the new waves and winds stirred by the future dynamics of economy and technology.

\section{BIBLIOGRAPHICAL NOTES}

A preliminary general overview of the historical evolution of intellectual (formerly 'industrial' and 'intellectual') property law from its commandeconomy origins to a regulatory framework based on equal rights and duties for entrepreneurs (in the classical system, consumers' interests are indirectly protected: see Chapters 4 and 5 below) may be gleaned from a series of works that include P. Torremans, Holyoak and Torremans Intellectual Property Law, Oxford University Press, 2016; I. Alexander and H. T. Gómez-Arostegui (eds), Research Handbook on the History of Copyright Law, Edward Elgar, 2016; A. Peukert, 'Intellectual Property: The Global Spread of a Legal Concept', in Kritika: Essays on Intellectual Property, Vol. I, Edward Elgar, 2015, 114; M. Cimoli, G. Dosi, K. E. Maskus, R. L. Okediji, and J. H. Reichman, Intellectual Property Rights, Oxford University Press; 2014; U. Suthersanen and Y. Gendreau (eds), A Shifting Empire, Edward Elgar, 2013; W.R. Cornish, D. Llewelyn and T. Aplin, Intellectual Property: Patents, Copyright, Trade Marks and Allied Rights, Sweet \& Maxwell, 2013; L. Bently, U. Suthersanen and P. Torremans (eds), Global Copyright, Edward Elgar, 2010; G. Dutfield and U. Suthersanen, Global Intellectual Property Law, Edward Elgar, 2008; L. Bently and B. Sherman, The Making of Modern Intellectual Property Law, Cambridge Intellectual Property and Information Law, 1999.

See also less recent seminal works, such as P. A. David, 'The Evolution of Intellectual Property Institutions', in A. Agambegyan et al. (eds), System Transformation: Eastern and Western Assessments, Macmillan, 1994; P. O. Long, 'Invention, Authorship, Intellectual Property, and the Origins of Patents: Notes Toward a Conceptual History', Technology and 
Culture, 1991, 846; F. Machulp and E. Penrose, 'The Patent Controversy in the Nineteenth Century', The Journal of Economic History, 1950, 1.

As recalled in the chapter, modern IP law was shaped to a large extent (not only at the level of the coordination and/or harmonization of national legal frameworks, but also in terms of common substantive principles) by the ground-breaking international conventions of the late 1800s: the Paris Convention (PUC) of 1883 on 'industrial property' and the Berne Convention of 1886 on copyright. These Conventions marked the first structured response to the ever-increasing integration of the world's most industrialized economies, which was both symbolized and stimulated by the great 'Universal Exhibitions' at the turn of the century. Here see, in particular, J. Ginsburg and S. Ricketson, International Copyright and Neighbouring Rights - The Berne Convention and Beyond, Oxford University Press, 2005. Among older works are, S. P. Ladas, The International Protection of Industrial Property, Cambridge University Press, 1930. See also, as concerns PUC, Y. Plasseraud and F. Savignon, Paris 1883. Genèse du droit unioniste des brevets, Paris, 1981, and, as concerns copyright, A. Bogsch, The Law of Copyright Under Universal Copyright Convention, Geneva, 1972.

The progressive contamination and hybridization among the paradigms that represent the classical regulatory dualism between 'industrial' (patents, trademarks) and 'intellectual' (copyright and neighbouring rights) property have been analysed in depth by specific essays, such as those gathered in G. B. Dinwoodie (ed.), Intellectual Property and General Legal Principles: Is IP a Lex Specialis?, Edward Elgar, 2015; A. Kur and V. Mizaras (eds), The Structure of Intellectual Property Law: Can One Size Fit All?, Edward Elgar, 2011. See also the seminal articles by J. H. Reichman: 'Legal Hybrids Between the Patent and Copyright Paradigms', Columbia L. Rev., 1994, 2432; and 'Charting the Collapse of the Patent-Copyright Dichotomy: Premises for a Restructured International Intellectual Property System', Cardozo Arts \& Entertainment L.J., 1995, 475; R. C. Dreyfuss, 'A Wiseguy's Approach to Information Products: Muscling the Copyright and Patent into a Unitary Theory of Intellectual Property', S. Ct. Rev., 1992, 195; H. Cohen Jehoram, 'Hybrids on the Borderline Between Copyright and Industrial Property Law', Rev. int. droit d'auteur, 1992, 75; J. Wiley, 'Copyright at the School of Patent', Univ. Chicago L. Rev., 1991, 119 (see further citations in the Bibliographical Notes to Chapters 2 and 3).

The evolution of over-protectionist trends in IP law to the point of reaching a veritable 'misappropriation explosion' (W. J. Gordon, 'On Owning Information: Intellectual Property and the Restitutionary Impulse', Va. L. Rev., 1992, 149), has been excellently described by 
J. H. Reichman in the works cited above as well as in 'Beyond the Historical Lines of Demarcation: Competition Law, Intellectual Property Rights, and International Trade After the Gatt's Uruguay Round', Brooklyn J. of Intern. L., 1993, 75. See further, R. M. Hilty, 'Five Lessons About Copyright in the Information Society, Reaction of the Scientific Community to Overprotection and What Policy Makers Should Learn', J Copyright Society USA, 2006, 103; M. Ricolfi, 'Is there an Antitrust Antidote Against IP Overprotection within TRIPS?', Marq. Intell. Prop. L. Rev, 2006, 305.

This phenomenon of 'over-protectionism' is also the result of the growing importance attached by major firms in the developed world to so-called intellectual asset management (IAM), that is, the exploitation of the monopolistic potential of intellectual property. For a summary, see O. Granstrand, The Economics and Management of Intellectual Property: Towards Intellectual Capitalism, Edward Elgar, 1999; W. Anson, 'How Intangible Assets Drive Capitalization', in Les Nouvelles, 1999, 133; G. Winter, 'Knowledge and Competence as Strategic Assets', in D. J. Teece (ed.), The Competitive Challenge, Ballinger Pub. Co., 1987.

The drive towards such exploitation is in turn linked to short-term managerial business policies (see the classic works by O. Williamson, in particular, 'Managerial Discretion and Business Behavior', Am. Econ. Rev., 1963, 1032, and Corporate Control and Business Behavior, Englewood Cliffs, 1970): policies are not always rational (B. Demil and X. Lecocq, 'Neither Market nor Hierarchy nor Network: The Emergence of Bazaar Governance', Organization Studies, 2006, Vol. 27, 1447).

More broadly, on the relationship between the emergence of new technologies based on users' demands and the consequent managerial and organizational models, see E. von Hippel, as quoted in fn 98.

The factors and processes that have driven industrialized countries' economies towards oligopolistic settings, have also (consequently) steered - so far - the evolution of contemporary commercial law towards basically US-type paradigms. For a broad overview of said factors and processes, and their impact on the transnational legal framework, see S. Frankel and D. J. Gervais, Advanced Introduction to International Intellectual Property, Edward Elgar, 2016; J. E. Stiglitz, 'Economic Foundations of Intellectual Property Rights', 57 Duke L.J., 2008, I, 693; J. Drexl, 'Intellectual Property Rights as Constituent Elements of a Competition-based Market Economy', in G. Ghidini and L. M. Genovesi (eds), Intellectual Property and Market Power - ATRIP Papers 20062007, Eudeba, University of Buenos Aires, 2008, 167; T. Dreier, 'Shaping a Fair International IPR-Regime in a Globalized World: Some Parameters for Public Policy', in I. Govaere and H. Ullrich (eds), 
Intellectual Property, Public Policy and International Trade, Brussels, 2007, 43; T. Cottier, 'The Doha Waiver and its Effects on the Nature of the TRIPS System and on Competition Law: The Impact of Human Rights', ivi, 173; J. H. Reichman, 'Nurturing a Transnational System of Innovation', ivi, 17 (and also in J. of Transnational L. \& Pol., 2007, 143); B. Klemens, Math You Can't Use - Patents, Copyright and Software, Brooking Institution Press, 2005; M. A. Lemley, 'Property, Intellectual Property, and Free Riding', Stanford Law and Economics, Olin Working Paper No. 291, 2004; K. E. Maskus, J. H. Reichman, 'The Globalization of Private Knowledge Goods and the Privatization of Global Public Goods', in Journal of International Economic Law, 2004, 279; K. Sell, Private Power, Public Law: The Globalization of Intellectual Property Rights, Cambridge University Press, 2003; N. Irti, L'ordine giuridico del mercato, Rome-Bari, 2003; J. R. Ostergard, The Development Dilemma: The Political Economy of Intellectual Property Rights in the International System, LFB Scholarly Publishing, 2002; S. D. Anderman, 'EC Competition Law and Intellectual Property Rights in the New Economy', Antitrust Bulletin, 2002, 285; D. Matthews, Globalizing Intellectual Property Rights - The TRIPs Agreement, Routledge, 2002; S. Sassen, Losing Control?, Columbia University Press, 1996.

Reaction to over-protectionist tendencies has occurred, as hinted in the text, along two legal and policy dimensions. The first is an increased awareness of the link between protecting intellectual property and safeguarding competition. For the extensive literature on the topic of relations between intellectual property and antitrust, see the Bibliographical Notes to Chapters 2, 3, 4 and 5.

A separate but often intertwined line of thought highlights the impact of the exercise of intellectual property rights on constitutionally guaranteed (i.e. fundamental) rights (like freedom of economic enterprise, competition, expression, information, research and teaching, etc.), at times elevated to the status of human rights. Conflicts with those rights can arise, as mentioned in the text, if the exploitation of intellectual property exceeds its essential function, i.e. offering protection against free riding. On this topic see S. Bannerman, International Copyright and Access to Knowledge, Cambridge University Press, 2016; C. Geiger, Research Handbook on Human Rights and Intellectual Property, Edward Elgar, 2015; A. Palmer, Patents, Human Rights and Access to Science, Edward Elgar, 2015; R. C. Dreyfuss and C. Rodrìguez-Garavito (eds), Balancing Wealth and Health: The Battle over Intellectual Property and Access to Medicines in Latin America, Oxford University Press, 2014; L. R. Helfer, Intellectual Property and Human Rights, Edward Elgar, 
2013; D. Matthews, Intellectual Property, Human Rights and Development, Edward Elgar, 2011; G. W. Austin and L. R. Helfer, Human Rights and Intellectual Property: Mapping the Global Interface, Cambridge University Press, 2011; W. Grosheide (ed.), Intellectual Property and Human Rights: A Paradox, Edward Elgar, 2010: here, worthy of special note are the essays by R. Cooper Dreyfuss, 'Patents and Human Rights: Where is the Paradox?' and C. McManis, 'Human Rights as a Constraint on Intellectual Property Rights: The Case of Patent and Plant Variety Protection Rights, Genetic Resources and Traditional Knowledge'; P. B. Hugenholtz, 'Copyright and Freedom of Expression in Europe', in R. Dreyfuss, D. Leenheer Zimmerman and H. First (eds), Expanding the Boundaries of Intellectual Property: Innovation Policy for the Knowledge Society, Oxford University Press, 2001. See also, with a special focus on copyright, P. Torremans (ed.), Intellectual Property and Human Rights: Enhanced Edition of Copyright and Human Rights, Kluwer Law, 2008: here see in particular, C. Geiger, 'The Constitutional Dimension of Intellectual Property', H. Grosse Ruse-Khan, 'Proportionality and Balancing within the Objectives for Intellectual Property Protection', and Y. Gendreau, 'Copyright and Freedom of Expression in Canada'.

As hinted in the main text, in the face of over-protectionist tendencies, the last two decades in particular have witnessed trends that propose new models for managing IPRs, aimed at sharing information/data/ technology. On this perspective (which encompasses von Hippel's 'user innovation' (see fn 98), more extensively dealt with in Chapters 2 and 3) see T. Riis, 'User Generated Law: Re-construing Intellectual Property Law in a Knowledge Society', in T. Riis (ed.), User Generated Law, Edward Elgar, 2016, 1; M. J. Madison, 'Information Abundance and Knowledge Commons', in T. Riis (ed.), User Generated Law, ibid., 28; M. J. Madison, 'Understanding Access to Things: A Knowledge Commons Perspective', in J. C. Lai and A. Maget Dominicé (eds), Intellectual Property and Access to Im/material Goods, Edward Elgar, 2016, 17; D. Beldiman, Innovation, Competition and Collaboration, Edward Elgar, 2015; O. Lobel, Talent Wants to Be Free: Why We Should Learn to Love Leaks, Raids, and Free Riding, Yale University Press, 2013; S. Haunss, Conflicts in the Knowledge Society, Cambridge University Press, 2013; R. C. Dreyfuss, D. Zimmerman, and H. First, Working Within the Boundaries of Intellectual Property, Oxford University Press, 2010; S. M. Maurer and S. Scotchmer, Open Source Software: The New Intellectual Property Paradigm, NBER Working Paper No. 12148, 2006 available at http://www.nber.org/papers/w12148; D. Rothen and W. Powell, 'The Frontiers of Intellectual Property: Expanded Protection Versus New Models of Open Science', Law and Social Science Law Review, 
2007, vol. 3; J. Lerner and J. Tirole, 'The Economics of Technology Sharing: Open Source and Beyond', NBER Working Paper No. 10956, 2004, available at: http://www.nber.org/papers/w10956; J. Lerner and J. Tirole, 'Efficient Patent Pools', American Economic Review, 2004, 691; J. Lerner and J. Tirole, 'The Scope of Open Source Licensing', JLEO, 2005, 21; L. Lessing, Code and Other Laws of Cyberspace, Basic Books, 2000; L. Lessing, The Future of the Ideas, Random House, 2001; R. Merges, 'A New Dynamism in the Public Domain', University of Chicago Law Review, 2004, 183. 